\title{
Procedimiento Inspector y proceso penal. Problemas no resueltos en la doble instrucción de delítos contra la hacienda pública en el Reino de España
}

\section{Inspection Procedure and Criminal Trial. Unresolved problems in the double instruction of offences against the national treasury in the Kingdom of Spain.}

\author{
JUAN LÓPEZ MARTÍNEZ \\ Universidad de Granada, España
}

RECEPCIÓN: 23/ 06/2016 • ACEPTACIÓN: 07/ 09/2016

\begin{abstract}
RESUMEN En el presente estudio se analizan las relaciones existentes en el derecho positivo español entre la articulación de las instrucciones del procedimiento de regularización de la deuda y el proceso por delito contra la Hacienda Pública. En él se pone de manifiesto que en la normativa que resulta aplicable no se establecen el conjunto de técnicas que de forma precisa articulen los derechos, deberes y garantías que han de observarse en ambos órdenes. En este sentido se analiza el concepto y efectos de la «noticia criminis» en el procedimiento de Inspección tributaria vigente en España; la naturaleza, el contenido y el alcance del traslado del «tanto de culpa» y, la operatividad y sus límites, del derecho a no autoinculparse en el procedimiento de regularización de deudas. Problemas que resultan nucleares en cualquier regulación que se establezca para la articulación de las relaciones entre procedimiento y proceso.
\end{abstract}

PALABRAS CLAVE Procedimiento de inspección - Proceso por delito contra la Hacienda Pública - Instrucción - «Noticia criminis» - «Tanto de culpa» - Derecho a no autoinculparse - Principios punitivos.

1. Catedrático de Derecho Financiero y Tributario. Universidad de Granada, España. Correo: jlopezm@ugr.es 


\begin{abstract}
The present study analyzes the existing relationships in Spanish statutory law by which instructions for debt regularization and trials for offences against the National Treasury are coordinated. It shows that the applicable regulations do not establish technical conditions that precisely express the rights, duties and guarantees to be observed in the two spheres. In this context we analyze the concept and effects of "Notitia criminis" in the Tax Inspection procedure in force in Spain; the nature, content and scope of the transfer of "share of guilt"; and the operability and limits of the right not to self-incriminate in the debt regularization procedure. These are central problems in any regulation established to coordinate relations between administrative procedures and criminal trials.
\end{abstract}

KEYWORDS Inspection procedure - Trials for offences against the National Treasury -Instruction - «Notitia criminis» - " Share of guilt " - Right not to selfincriminate - Punitive principles.

\title{
SUMARIO
}

i. La necesaria articulación jurídica entre la instrucción del procedimiento inspector y el proceso por delito frente a la hacienda pública.

ii. Principales problemas pendientes:

a. Concepto y efectos de la noticia criminis.

b. Naturaleza, contenidos y efectos del traslado del tanto de culpa.

b. Operatividad y límites del derecho a no autoinculparse en el procedimiento regularizador de deudas.

iii. A modo de conclusión. 
i. La necesaria articulación jurídica entre la instrucción del procedimiento inspector y el proceso por delito frente a la hacienda pública.

En España, el modelo de relaciones existentes entre regularización tributaria y proceso por delito frente a la Hacienda Pública ha transitado por diferentes etapas tras el primer antecedente del actual tipo de delito contra la Hacienda Pública que introduce la ya lejana L. 50/1997, de 14 de noviembre sobre reformas urgentes de reforma fiscal ${ }^{2}$. En una primera etapa, se estableció un sistema de prejudicialidad tributaria en la que la única legitimada para denunciar un delito fiscal era la Administración tributaria cuando la liquidación administrativa de la deuda fuera firme en vía administrativa. Dicho sistema se alteró, por completo, por la Ley Orgánica 2/ 1985 que suprimió la prejudicialidad ${ }^{3}$, estableciendo que la Administración estaba obligada a realizar la denuncia desde el mismo momento en que tuviese indicios -noticia criminis- de la posible comisión de un delito contra la Hacienda Pública, en cumplimiento de las exigencias constitucionales (Ss.TC $2 / 81,77 / 83$ ). A partir de dicho momento el procedimiento administrativo -sea sancionador o de regularización- debería paralizarse al elevar el correspondiente «tanto de culpa» a la jurisdicción penal ${ }^{4}$.

Este sistema, con matices aún vigente en España, situó el eje de las relaciones establecidas entre regularización y proceso en el momento en el que deberían paralizar las actuaciones de inspección para preservar las garantías del futuro imputado en el procedimiento administrativo, es decir, en el concepto y efectos de la denominada «noticia criminis»; en determinar las verdaderas consecuencias del traslado del «tanto de culpa»; en precisar la naturaleza jurídica del subprocedimiento administrativo previo ${ }^{5}$; en determinar el diferente alcance y valor de las pruebas obtenidas en la instrucción del procedimiento y el proceso -y el auténtico significado

2. Tras la suspensión del requisito del requerimiento al pago por el competente funcionario administrativo recogido en el capítulo de las falsedades del Código Penal de 1879.

3. Para un análisis de la indicada reforma ver, entre otros, a Pont I Clemente, J-F. (1987) p. 1237 y ss.

4. El sancionador se paralizaría, por la exigencia del principio ne bis in ídem. El de regularización no tanto por la operatividad de dicho principio sino como una consecuencia del principio de seguridad jurídica y del principio de prevalencia de la jurisdicción penal.

5. Regulados en la actualidad en los arts. 32 y ss. del Reglamento General del Régimen Sancionador Tributario (RD. 2063/2004, de 15 de octubre). 
de su traslación- .... En definitiva, en acotar jurídicamente la diferente posición del obligado tributario y del imputado en un delito frente a la Hacienda Pública ${ }^{6}$

Con el sistema vigente en la normativa española, como desarrollaremos a lo largo del presente trabajo y hemos avanzado en otro lugar ${ }^{7}$, el modelo de relaciones establecidas entre la instrucción del procedimiento de regularización y la del proceso, no soluciona, al menos con la nitidez necesaria en un marco de relaciones dónde se ventilan derechos colectivos e individuales de extraordinaria importancia, por ello, puede resultar útil a los propósitos del presente estudio, que presentemos, el modelo de relaciones diseñadas por la L.O. 7/ 2012, fruto de la nueva redacción que otorga al art. 305.5 del Código Penal (en adelante CP), que a nuestro juicio establece una nueva «prejudicialidad» fáctica, al permitir que la Administración liquide la deuda vinculada al delito, y proceda a su recaudación por los procedimientos administrativos usuales, aunque se traslade el correspondiente «tanto de culpa» a la jurisdicción penal ${ }^{8}$. No obstante, como la normativa indicada, no modificó la Ley General Tributaria (en adelante LGT), este modelo no pudo entrar en vigor, hasta la modificación de ésta última por la Ley 34/ 2015 de 21 de septiembre. ${ }^{9}$

6. Problemas que a nuestro juicio, como desarrollaremos a lo largo del presente trabajo, no se encuentran resueltos satisfactoriamente por nuestro actual derecho positivo y precisan de una regulación más acorde a los intereses y garantías que se encuentran en juego.

7. En este sentido nos remitimos a nuestra publicación "Problemas pendientes en las relaciones entre la regularización tributaria y el proceso penal a la luz de la reformas de la Ley General Tributaria". Trabajo del que extraemos algunas de las consideraciones contenidas en el presente estudio. (Vid. Rev. Quincena Fiscal ำ 4. 2016).

8. Se establecía un nuevo sistema - que contradecía lo regulado en el aquél momento vigente art. 180 de la LGT y su normativa de desarrollo, que no fue derogada- y que a su vez era poco compatible, por dirigirse en la dirección opuesta, al incidir en el sistema de garantías cautelares contempladas en el art. 81 de la LGT, fruto de la L 12/ 2012. Es la consecuencia de la legislación por aluvión, sin análisis y sin sistema a la que tan acostumbrada nos tiene nuestro legislador, singularmente en materia tributaria.

9. Manteniéndose, el modelo de relaciones vigente hasta septiembre de 2015. Ya que la ley ahora reformada, precisamente por esta necesidad de armonizar lo contemplado en el ya no tan nuevo artículo 305 del CP con la regulación de los procedimientos aplicativos de los tributos, incorpora todo un título VIạ, de nuevo cuño, que pretende regular, precisamente, las «actuaciones y procedimientos de aplicación de los tributos en los supuestos de delito contra la Hacienda Pública». 
Si presentamos, a modo de contexto necesario para el presente trabajo, la exégesis de las líneas esenciales de la reforma ${ }^{10}$, el nuevo sistema perfila el conjunto de las relaciones estudiadas en torno a las siguientes consideraciones: cuando sea posible se producirá en vía inspectora la separación de dos liquidaciones, la de la deuda vinculada al delito y la de la deuda no vinculada. La de la deuda no vinculada se desarrollara por los procedimientos de liquidación, recaudación y revisión vigentes; la de la deuda vinculada al delito, si bien mantiene su estructura tradicional en relación a su inicio y tramitación -las del procedimiento inspector- incorporará significativas modificaciones en relación con las fases de terminación, recaudación y revisión. A los efectos del presente estudio, las características más representativas de este nuevo formato de relaciones entre procedimiento y proceso, son las que siguen:

En primer lugar, se precisará, para liquidar, la pertinente autorización del órgano administrativo competente para interponer la denuncia o la querella. No obstante, la nueva normativa afirma de forma tajante, sin utilizar el «podrá» del CP, que se "continuará la tramitación del procedimiento", lo que significa que salvo en los tres supuestos tasados establecidos en el nuevo art. 251 de LGT ${ }^{11}$, se anula de facto la operatividad de la suspensión de la instrucción del procedimiento de regularización - hasta ahora vigente- tras la aparición de la «noticia criminis», suspensión, que se traslada al momento de la liquidación.

De igual forma, es necesario destacar que en esta tramitación especial, no serán objeto de análisis -ni en sede administrativa ni en revisión- las cuestiones que no guarden relación con la cuantificación de la deuda, singularmente los plazos de regularización y las demás cuestiones o defectos, calificados de procedimentales (sic). En consecuencia, ningún caso podrán producir la extinción de la deuda, sin perjuicio de lo que pueda derivarse de la devolución del expediente por inexistencia de delito.

En tercer lugar, se establecerá un periodo de alegaciones -que no es exactamente el inicialmente establecido y luego derogado en el art. 180 de la LGT en su versión de 2004-. Periodo de alegaciones que, según pensamos, al menos podrá ser utilizado por

10. Obviamente en relación a las nuevas relaciones que se establecen entre el procedimiento de regularización de deudas y el proceso por delito frente a la Hacienda Pública. Para un mayor desarrollo recomendamos la lectura, entre otros, de Montero Domínguez (2012); Beltrán Girón, F. (2012), Ayats Vergés y De Juan Casadevall (2013), López Díaz (2015) y Palao Taboada (2015).

11. Cuando pueda ocasionar la prescripción del delito; cuando no pueda determinarse con exactitud el importe de la liquidación; o cuando la propia investigación administrativa pudiera perjudicar la comprobación de la defraudación. 
el administrado para discutir la vinculación o no al delito de la parte de la deuda que se quiere regularizar en este procedimiento especial. Una vez dictada la liquidación se pasará el tanto de culpa y se entenderá por finalizado el procedimiento de regularización ${ }^{12}$.

Este nuevo modelo de relaciones precisa que el inicio del plazo para el pago voluntario de la deuda será posterior a la admisión de la denuncia o querella. A partir de dicho momento -salvo la suspensión ordenada por el juez instructorno se paralizará la acción de cobro, rigiéndose por los procedimientos ejecutivos al uso, salvo, con carácter general, en lo que concierne a la prohibición de enajenar bienes y derechos embargados hasta que la sentencia que confirme la liquidación sea firme. La inadmisión de la denuncia o querella supondrá la retroacción de actuaciones al momento anterior al que se dicte la propuesta de liquidación, procediéndose a expedir un acta, que se tramitará según su naturaleza ${ }^{13}$.

Los presentados, son a nuestro juicio, los parámetros esenciales de la nueva legislación en relación con la temática abordada en el presente estudio. De su estudio resulta fácilmente deducible que el nudo esencial de dicha reforma presenta como único objetivo anticipar la recaudación de la deuda en supuestos en los que pueda existir el delito contra la Hacienda Pública, es decir: liquidar y recaudar las deudas vinculadas al delito, mientras que se instruye el proceso. No obstante la reforma no va más allá. Lejos de incidir sobre los problemas pendientes, los obvia, su finalidad es exclusivamente recaudatoria ${ }^{14}$. En otros términos, con la nueva modificación normativa se mantiene la situación fáctica hasta ahora existente, que, como decíamos, resulta difícilmente compatible con los derechos y garantías de los administrados en su doble condición- ahora- de obligado tributario y de imputado.

12. Se abstendrá de iniciar o continuar el procedimiento sancionador. Con lo que pretendidamente, el análisis de la reforma se sitúa en un plano distinto a la operatividad del ne bis in ídem.

13. Teniendo en cuenta cuanto antecede, se sostiene que el nuevo modelo de relaciones mantiene la preferencia del orden penal basada en tres aspectos: corresponde al juez la posibilidad de suspensión de las actuaciones administrativa de cobro; finalizado el proceso penal, la liquidación tributaria, en su caso, deberá ajustarse a los hechos que el juez declare probados; de no apreciarse la existencia de delito por inexistencia de obligación, la liquidación administrativa será anulada, aplicándose las normas generales sobre devoluciones y reembolsos de las garantías.

14. En esta línea ver, entre otros, a Rancaño Martín (2014) p. 92 y ss. 
Para mantener cuanto aquí sostenemos, baste recordar que los procedimientos de aplicación de los tributos, singularmente el procedimiento inspector, tienen por objeto el control al sometimiento de la legalidad de los comportamientos debidos de los administrados. Para ello el ordenamiento les atribuye una serie de funciones - art. 141 LGT y 166 a 169 del Reglamento General de las actuaciones y procedimientos de gestión e inspección Tributaria y de desarrollo de normas comunes de los procedimientos de aplicación de los tributos (en adelante RGGIT) - que habrán de ser desarrolladas, precisamente, en los procedimientos regularizadores. De entre todas ellas, el art. 145 de la LGT, presenta como objeto nuclear del procedimiento de inspección la comprobación e investigación del cumplimiento de las obligaciones tributarias y la práctica, en su caso, de la regularización de la situación tributaria del obligado a través de las oportunas liquidaciones. Es decir, la liquidación es el resultado de las actuaciones previas de comprobación e investigación, y su consecuencia es la recaudación. Por este motivo, hemos de comenzar enfatizando que serán estas actuaciones previas, -las de instrucción del procedimiento de regularización- y no tanto las de liquidación y de recaudación, las que habrán de ser armonizadas con las que se desarrollan, o debieran ser desarrolladas, en la instrucción de un proceso penal incoado por un delito contra la Hacienda Pública ${ }^{15}$.

Precisamente por la idea indicada, la reforma que L.O. 7/ 2012 incorpora en el art. 305 CP y el título de nuevo cuño incorporado en la modificada LGT, que establecen la posibilidad de la liquidación y la recaudación de las deudas tributarias regularizadas vía inspección estando pendiente la instrucción del proceso penal, por mucho que suponga una nueva visión de las relaciones entre procedimiento y proceso, no condiciona, ni resuelve, la problemática que envuelve el tránsito entre una y otra instrucción, sencillamente, porque no era su objetivo, puesto que éste, reiteramos, por paradójico que parezca, no es otro que el estrictamente recaudador ${ }^{16}$.

15. Ruiz García (2013) p. 63 y 64.

16. A este respecto basta contemplar la exposición de motivos de la reforma incorporada tanto en la modificación del tipo penal: "...con esta reforma se trata de eliminar situaciones de privilegio y situar al presunto delincuente en la misma posición que cualquier otro deudor tributario, y al tiempo se incrementa la eficacia de la actuación de control de la Administración: la sola pendencia del proceso judicial no paraliza la acción de cobro pero podrá paralizarla el Juez siempre que el pago de la deuda se garantice o que el Juez considere que se podrían producir daños de imposible o difícil reparación"; como de la LGT, que alude a la idea de superar el diferente e injusto trato que frente al infractor administrativo presenta el imputado por delito en relación al pago 
La necesidad de armonizar las indicadas relaciones, surge de la propia consideración técnica del tipo penal del delito contra la Hacienda Pública17. En consecuencia, la problemática que subyace sobre las conexiones ${ }^{18}$ entre el procedimiento de regularización de la deuda y el proceso penal por delito frente a la Hacienda Pública tiene su causa en el tipo penal que lo origina, de manera que como ha puesto de manifiesto entre otros muchos Ruiz García, mientras éste se mantenga existirá una conexión objetiva entre procedimiento y proceso que desarrollará una serie de interconexiones evidentes ${ }^{19}$.

No obstante, la verdadera dimensión de la problemática que queremos presentar en nuestro estudio no reside tanto en las conexiones objetivas que el umbral económico del tipo penal proyectará sobre ambas instrucciones, como en el hecho de que procedimiento administrativo y proceso no solo tienen finalidades diferentes ${ }^{20}$, sino que se rigen por normas, técnicas y principios que en ocasiones puede ser difícilmente conciliables.

Son muchos los aspectos que la doctrina ha ido poniendo de manifiesto para plasmar las diferencias estructurales existentes entre un procedimiento

o garantía establecida para eludir la ejecutoriedad del acto administrativo. Es decir, liquidar y recaudar la deuda en situación de pendencia del proceso penal. En esta misma línea, se puede consultar, entre otros, a Montero Domínguez (2015) p. 166.

17. En efecto, como ha señalado Iglesias Capellas, mientras que exista un umbral económico a partir del cual la infracción tributaria adquiere relevancia penal, para garantizar los derechos e intereses que asisten al administrado, a la Administración y, a la Jurisdicción, se ha de regular adecuadamente el tránsito entre la fase administrativa y la fase judicial, estableciendo con precisión, tanto los efectos de la litispendencia penal sobre las autotutelas administrativas, como los efectos de la aplicación prejudicial de la norma tributaria por el juez que ha de instruir el proceso penal. Iglesias Capellas (2013) p. 42.

18. Para su análisis recomendamos la lectura de Moreno Catena (2014).

19. Por un lado, las actuaciones de comprobación e investigación en el procedimiento de regularización van a poder ser utilizadas en el proceso penal; por otro, los hechos probados en el proceso penal pueden ser determinantes en el procedimiento tributario Ruiz García (2011) p. 725 y ss.

20. En el procedimiento de regularización de la deuda se persigue obtener los recursos necesarios para la financiación de los gastos públicos en complimiento del deber general de contribuir; en el proceso penal, la represión de los actos punibles mediante la imposición de una pena con la finalidad de conservar el orden público. En Este sentido vid a Ruiz García (2011) p. 725. 
administrativo de aplicación de los tributos y los procesos21, para la finalidad de este trabajo baste, por el momento, con indicar, por un lado, aquellas que aluden a la diferente posición jurídica del obligado tributario y el imputado en el curso de la instrucción del procedimiento y el proceso y, por otro, a las que se manifiestan en la práctica y a la carga de la prueba que van a ser exigidas en sendas instrucciones22.

En relación a la diferente posición jurídica del obligado y del imputado, hemos de llamar la atención, en primer lugar, que el instructor penal podrá ejercitar poderes que le van a permitir una mayor injerencia en la esfera personal y patrimonial del imputado en relación con los que dispone la Inspección de los tributos en los procedimientos de regularización tributaria23. En segundo término, hemos de precisar que, por el contrario, en relación a la práctica y a la carga de la prueba en los procedimientos de aplicación de los tributos, la carga objetiva de la prueba que recae sobre la Administración, se ve extraordinariamente facilitada, no solo por el cumplimiento, bajo la amenaza de sanción, de los deberes de colaboración propia o de terceros, sino también por una pléyade de presunciones, estimaciones y otras técnicas valorativas que facilitarán la determinación de la deuda tributaria, pero que se encuentran extraordinariamente limitadas en el proceso penal, dónde rige con toda su intensidad el principio de presunción de inocencia y el derecho a no autoinculparse 24.

La constatación de estos elementos no significa que los principios que resultan operativos en las diferentes manifestaciones del Ius puniendi estatal limiten su ámbito de aplicación al procedimiento sancionador o al proceso por delito contra la Hacienda Pública, ya que dicha afirmación, o su contraria, dependerá de cómo se articulen las relaciones entre procedimiento de aplicación de los tributos y procedimiento sancionador o proceso, para que debamos sostener

21. O los procedimientos sancionadores en los que resultan aplicables los principios del «Ius puniendi» del Estado. En este sentido nos remitimos in extenso a nuestros trabajos (2001-I-) (2001-II-), (2003), (2008).

22. En esta misma línea ver al profesor prof. Ruiz García (2011) p. 725 y ss. Vid. También nuestro trabajo

López Martínez (2016).

23. Ruiz García (2011) p. 726. En esta misma línea, recomendamos la lectura de Calvo Vérgel (2014) p. 21 y ss.

24. Ruiz García (2011) p. 726. Quien también nos podrá de manifiesto, como se desarrollará en otro momento del presente trabajo, que el derecho a no declarar contra sí mismo no limita su ámbito de aplicación al ordenamiento penal, sino que puede desplegar operatividad - en función de cómo se articulen las relaciones entre procedimiento y proceso, añadimos nosotros- en los procedimientos de regularización de la deuda, singularmente en el procedimiento de inspección. 
que han de desplegar su operatividad en los procedimientos de regularización tributaria25. A nuestro juicio, es en esta última afirmación dónde hemos de localizar el eje central de la problemática que subyace a la conexión existente entre ambas instrucciones que, según pensamos, no se encuentra resuelta de forma respetuosa con los derechos y los intereses que han de garantizarse tanto en el procedimiento como en el proceso.

Todo cuanto antecede, es decir, que ambas instrucciones tengan por objeto los mismos hechos y que sin embargo se rijan por normas, técnicas y principios no siempre compatibles, nos sitúa ante la verdadera problemática, como decíamos, no resuelta, ni en la nueva regulación, ni en la normativa que la precede. Problemática, que se pone groseramente de manifiesto cuando el procedimiento de aplicación de los tributos es utilizado -con la ignorancia del obligado tributariopara acumular material probatorio que será ulteriormente empleado en el proceso penal -en más ocasiones de las que sería de desear retrasando deliberadamente su inicio-; y se pone igualmente de manifiesto, cuando los instrumentos utilizados en el orden punitivo para lograr las pruebas de los hechos son posteriormente relevantes en la determinación de la deuda tributaria 26

Precisamente, para evitar desajustes en la articulación jurídica de los principios y derechos aplicables en la instrucción realizada en regularización y la desarrollada en sede penal, se han de estudiar las normas que regulan el tránsito entre procedimiento y proceso para poder enjuiciar, en sus justos términos, su alcance y sus posibles soluciones. Y por esta razón en los siguientes epígrafes presentaremos los principales problemas que se generan por la inexistencia de una regulación que precise correctamente la indicada conexión.

\section{i. $\quad$ Principales problemas pendientes:}

En la extensión que resulta razonable en un trabajo de las presentes características sería materialmente imposible presentar toda la problemática que genera el actual modelo de relaciones entre regularización y proceso por delito fiscal para la aplicación, en cada instrucción, de los principios, derechos y reglas que le son propias. Hemos de tener presente que, tanto si se ordena, por

25. Para profundizar sobre este tema, recomendamos la lectura, entre otros trabajos, de los profesores Palao Taboada (2013) p. 25 y ss. y Lozano Serrano (2015) p. 1 y ss.

26. En esta misma línea se debe consultar a Ruiz García (2011) p. 729. 
un lado, paralizar las actuaciones de regularización con la aparición de los indicios «noticia criminis» de la posible comisión de un delito frente a la Hacienda Pública (como sucedía hasta la reforma analizada), como si se sigue instruyendo en sede de regularización (como se contempla tras la reforma), al pasar el correspondiente «tanto de culpa» al órgano jurisdiccional competente y, en consecuencia, trasladar los datos y pruebas obtenidos en regularización a la propia instrucción del proceso, se apuesta por un modelo de relaciones en los que existen una vía de comunicación que, a nuestro juicio, no se encuentra suficientemente atemperada a los intereses y derechos que se ventilan en los diferentes órdenes estudiados. Nuestra pretensión es más modesta. Nos limitaremos a presentar las principales aristas de tres problemas esenciales, según pensamos, tradicionalmente no resueltos y que la nueva legislación, lejos de resolver, consagra, ahora, con el valor de la letra impresa en el Boletín Oficial de Estado.

a. Concepto y efectos de la noticia criminis.

El primer problema que queremos presentar alude al propio concepto y a los efectos jurídicos que se han de desplegar con la aparición de los indicios delictivos en el procedimiento de regularización tributaria y, para conseguir nuestro propósito, conviene comenzar diferenciando ${ }^{27}$ el momento en el que el instructor del procedimiento de regularización comienza a obtener indicios de la posible existencia de un delito, «noticia criminis», del momento en el que se produce el traslado del «tanto de culpa». El primero, obviamente anterior al traslado del «tanto de culpa», ha de cambiar por completo la propia naturaleza del procedimiento de regularización puesto que a partir de dicho instante altera su teleología y los propios derechos y deberes de los obligados en el procedimiento.

El alcance de la mutación de la naturaleza del procedimiento de regularización tras la aparición de la «noticia criminis», dependerá, claramente, de cómo se hayan diseñado las relaciones entre la instrucción del procedimiento y la del proceso, puesto que la comunicación ilimitada de los resultados y pruebas entre ambas instrucciones ordenada por nuestro derecho positivo -antes y después de la reforma- ha de hacernos demandar la aplicación de determinados

27. Como ya adelantamos en otro lugar López Martínez (2016) p. 37 y ss. 
principios punitivos en el procedimiento de regularización, como única forma de garantizarlos en el proceso ${ }^{28}$.

Este primer elemento exige, frente a lo que pudiera pensarse, que la articulación de las indicadas relaciones venga presidida por el respeto a los principios que resultan operativos en cada orden. Y a nuestro juicio, ello significa que han de regularse con precisión: en primer lugar, las implicaciones que en el regularizador tributario ha de tener el derecho a ser informado; en segundo término, la operatividad, en el procedimiento y, en el proceso, del derecho a no autoinculparse; y, como corolario de todo lo anterior, la incidencia y su modulación, en ambas instrucciones, de los principios de culpabilidad y presunción de inocencia.

Si analizamos la actual normativa hemos de señalar que nada de ello se ha precisado, al menos con la claridad demandada por la operatividad de los derechos y principios aplicables, y aunque por lo general, la doctrina que se ha ocupado del tema limita su análisis al estudio de la incidencia en ambas instrucciones del derecho a no autoinculparse, pensamos que para su recto entendimiento se han de tener en cuenta, con carácter prioritario el indicado trasvase de datos y pruebas, y su alcance, como única forma de obtener una visión más nítida de la penetración de los principios aplicables en el proceso y en el procedimiento que se ha de producir cuanto en el primero surgen los primeros indicios de la existencia de elementos que configuran el tipo penal.

Para ello, es esencial tener en cuenta que el derecho a ser informado de la acusación forma parte de los derechos de defensa enumerados en el art. 24.2 CE, pero no sólo es un derecho más de defensa, sino que es, o debe ser, el primer derecho de defensa que condicionará en su exacto cumplimiento la propia efectividad de los restantes. Se precisa en consecuencia, determinar el alcance del derecho a ser informado de la acusación, y el momento en el que se

28. En consecuencia, para evitar la mixtificación de los principios propios de la regularización y el orden punitivo se ha de defender el establecimiento de unas relaciones que permitan la operatividad, en uno y en otro, de los principios que le son propios. Y para ello, como hemos defendido en otro lugar -López Martínez (2001 -I), (2001-2-) y (2016)-, en relación a la comunicación de datos entre el regularizador y el sancionador tributario, no creemos que se haya de reivindicar la absoluta incomunicabilidad de los datos y pruebas, puesto que a nuestro juicio, que los datos obtenidos en el procedimiento de regularización sean utilizados en la instrucción del proceso, no tiene por qué suponer, con carácter apriorístico, una lesión a derechos constitucionales del orden punitivo, siempre que su incorporación no viole ningún derecho constitucionalmente protegido en el orden sancionador. 
ha de exigir el cumplimiento de dicho derecho. E insistimos, en función de cómo se articulen las relaciones entre procedimiento y proceso, en qué instrucción puede empezar a ser operativo ${ }^{29}$.

En otros términos, para preservar los derechos a la defensa en el proceso no sólo se ha de analizar la fase procedimental en la que se ha de realizar el traslado del «tanto de culpa», ni, como veremos, el alcance de dicho traslado, sino singularmente, la necesidad de advertir al contribuyente sujeto a un procedimiento de regularización, de la hipotética incorporación de los datos y pruebas obtenidos en su instrucción, en un ulterior proceso por delito frente a la Hacienda Pública ${ }^{30}$.

A lo largo del presente trabajo hemos de pronunciarnos sobre todos los anteriores aspectos, por ahora baste dejar apuntado que el momento en que se ha de advertir de la existencia de la «noticia criminis», con independencia de que se prosigan las actuaciones para consolidar dicha sospecha y paralizar las correspondientes actuaciones para elevar el tanto de culpa,- o proseguir las instrucción hasta liquidar la cuota vinculada al delito- ha de ser cuando aparecen los primeros indicios, ya que el derecho a ser informado, exige que " esta información sea tempestiva, esto es, que se proporcione al sujeto tan pronto como el procedimiento se rija contra él y, en todo caso, con carácter previo

29. En este sentido, y en relación al contenido del derecho, nuestro Tribunal Constitucional ha señalado que: "como consecuencia del principio de información derivado del art. 24.2 C.E., habrá de contener todos los datos necesarios para permitir al interno obtener un exacto conocimiento de los hechos imputados y poder defenderse de los mismos" FJ. IVo. STC 297/ 1993. Mientras que en relación al momento en el que debe ser materializado, nuestro Máximo Intérprete ha señalado que toda persona a la que se le atribuya fundadamente un hecho punible, ha de tener acceso al proceso, y que el mismo lo sea, sin dilaciones, en condición de imputado, para garantizar la plena efectividad de su derecho a la defensa y evitar que puedan producirse contra ella, aún en fase de instrucción judicial situaciones de indefensión (Ss.TC 44/ 1985 y 135/ 1989), "ya que el conocimiento de la imputación forma parte del contenido esencial del derecho fundamental a la defensa en la fase de instrucción" STC 186/ 1990, de 15 de noviembre. FJ. №.

30. Hemos de tener en cuenta que en nuestro ordenamiento -singularmente en la LGT- no se impone a la Administración las garantías del Ius puniendi hasta que no se inicia formalmente el proceso, pero ello ha de tamizarse en función del establecimiento de la comunicabilidad de pruebas entre ambas instrucciones vigente en nuestro ordenamiento, de esta forma, si en un procedimiento de regularización el obligado resulta sospechoso de un ilícito -imputado material-, se le ha de comunicar en ese preciso momento, para que pueda ejercitar los derechos que le asisten con anterioridad a que se haya incoado formalmente -imputado jurídico- el correspondiente proceso punitivo. Vid. Pérez Nieto, R. (2013) p. 100-101. 
a cualquier actuación que pueda resultar autoincriminatoria"31, sin que ello signifique, que el contribuyente pueda oponerse, por tal razón, al cumplimiento de todos los deberes de colaboración exigidos en vía de regularización ${ }^{32}$.

En esta línea de planteamiento, se ha de tener en cuenta que, como ha puesto de manifiesto Palao Taboada, en el análisis de las actuaciones de la Administración Tributaria relacionadas con el proceso por delito fiscal, hemos de diferenciar aquellas actuaciones previas al pase del «tanto de culpa», de aquellas que pueden realizarse en el curso de la instrucción del proceso propiamente dicho, siendo así que la aparición de los primeros atisbos de su existencia, debe llevar a la Administración Tributaria a comprobar si los indicios detectados tienen la consistencia suficiente para paralizar las actuaciones y remitirlos a los Tribunales, en la legislación ahora derogada, o liquidar la deuda vinculada al delito tras la nueva reforma ${ }^{33}$. Pero nada más, en consecuencia, en estas actuaciones no se deben buscar medios de prueba que justifiquen la condena penal ${ }^{34}$.

Teniendo en cuenta cuanto antecede, hemos de analizar cuál es la naturaleza de esta fase pre-procesal que ordenada por el Reglamento sancionador tiene como único objetivo determinar si existen suficientes indicios para su remisión ${ }^{35}$, máxime, una vez suprimido el trámite de audiencia contemplado en el art. 180 de la LGT en su versión 2004 en el que se suscitaban estas cuestiones, puesto que la fijación del momento inicial y final de estas actuaciones -ya no identificables

31. Aneiros Pereira (2002) p. 17.

32. Cuestión sobre la que nos pronunciaremos en otro momento del presente estudio.

33. Palao Taboada (2013) p. 42 y ss.

34. Como afirma Ruiz García, las actuaciones solo han de ir encaminadas para disipar las dudas que han de existir para el traslado del «tanto de culpa». -Ruiz García (2011) p. 739.

35. Hemos de tener en cuenta que la remisión del expediente al Ministerio Fiscal o el traslado del Tanto de culpa al juez penal es un acto reglado (art. 32.2 RPST) en el que intervienen diversos órganos administrativos y que tiene un contenido predeterminado por la normativa: $1^{\text {}}$ ) El informe de la unidad o equipo responsable de la comprobación -al que deberá acompañarse las pruebas obtenidas en el procedimiento de regularización junto con las diligencias practicadas- (en consecuencia, coincidimos con Iglesias Capellas (2013-II-) p. 133 y 134 en advertir que su contenido puede diferenciarse entre la parte «fáctica» y la «jurídica», obviamente, a los efectos del presente trabajo con un distinto alcance); $2^{\circ}$ ) El informe de la Unidad del delito Fiscal; $3^{\circ}$ ) El informe de los órganos consultivos. 
exclusivamente con el procedimiento de regularización ${ }^{36}$ - es una exigencia del principio de claridad procedimental, ya que el contribuyente ha de tener el necesario conocimiento de en qué procedimiento se encuentra para poder ejercitar, o no, sus derechos ${ }^{37}$.

Todo lo anterior incide en la importancia del derecho a la información y que éste sea tempestivo, en consecuencia, que sea exigible desde el primer momento en el que surgen los indicios -y se investigan dichos indicios-, de forma que el obligado sujeto a regularización, puesto que los datos puede ser utilizados en un proceso posterior, tenga derecho a conocer de la verdadera naturaleza de las actuaciones que se le están practicando, para poder ejercitar, desde este momento, los derechos que rigen las nuevas actuaciones, singularmente, como veremos, su derecho a no autoinculparse. Y es justamente en este momento en el que las actuaciones mutan su naturaleza cuando entran en juego otros principios y otros derechos diferentes a los que son propios del procedimiento de regularización. Incluso en las actuaciones previstas en la nueva normativa para liquidar la cuota vinculada al delito. En otros términos, no era necesario el inicio del subprocedimiento ${ }^{38}$ previo al traslado del «tanto de culpa», ni la segregación entre cuota vinculada o no al delito en la normativa ahora vigente, basta con que existan los primeros indicios, y se proceda a su investigación, lo que causará que la estructura y el objeto de las actuaciones de comprobación e investigación se

36. Razón por la que parece lógico que en el curso de dichas actuaciones la inspección de los tributos tampoco disponga de la totalidad de facultades que se otorgan en el procedimiento de regularización, Y en este sentido, coincidimos de nuevo con Ruiz García, J, R. (2011) p. 739. en que debe limitarse, esencialmente la facultad de emitir requerimientos bajo la amenaza de sanción al obligado.

37. Hemos de tener en cuenta que lege data, nos encontramos con un subprocedimiento que si bien formalmente se encuentra insertado en el procedimiento de regularización, su objeto difiere de la investigación de la deuda, de manera que, a nuestro juicio, será esta diferencia en el objeto de las actuaciones a realizar -antes y después del inicio del subprocedimiento, concretamente desde que se localizan los primeros indicios de la «noticia criminis»-, la que ha de condicionar tanto las facultades de la Administración, como los derechos del obligado. (Ruiz García (2011) p. 738).

38. En él resulta evidente que su especial situación condiciona "tanto las facultades de la Administración como los derechos del sujeto pasivo" (Ruiz García (2011) p. 738). 
alteren para conseguir los datos y las pruebas necesarias para consolidar dichos indicios ${ }^{39}$.

A nuestro juicio, la cuestión abordada es de extraordinaria importancia, ya que la fijación de este instante en el que se muta la naturaleza jurídica de las actuaciones de regularización y el recto cumplimiento del derecho a la información del obligado, aún no imputado, puede asegurar las garantías y las obligaciones que han de sustanciarse en ambas instrucciones o provocar un automatismo criminalizador de cualquier defraudación tributaria y conferir a los órganos administrativos de una valoración de potestad preprocesal ilimitada sin sujeción al control jurisdiccional ${ }^{40}$.

A pesar de ello, como decíamos, en el actual sistema positivo no se perfila con la claridad que sería de desear, ni este momento exacto en el que se materializa la existencia de la «noticia criminis», ni los efectos que su existencia debería desplegar en la articulación jurídica de las actuaciones que se sustancien, desde la existencia de la «noticia criminis» en sede de regularización, singularmente, el derecho a la información sobre la naturaleza de las actuaciones desarrolladas a partir de dicho momento. En consecuencia, será el recto criterio del actuario quien deberá considerar que los indicios son los suficientemente representativos, bien para paralizar las actuaciones, absteniéndose de seguir el procedimiento, y remitir las actuaciones practicadas con las diligencias en las que consten los hechos y circunstancias que, a su juicio, determinen la posible responsabilidad penal, con la anterior normativa, bien para comunicar tal hecho

39. De manera que, como continua afirmando el profesor Palao si la Administración no comunica al contribuyente sus sospechas de la posible existencia de un delito, en el preciso momento en el que se presentan, retrasando indebidamente el inicio del procedimiento previo al traslado del tanto de culpa, - 0 la división de la cuota vinculada o no al delito tras la nueva normativa, añadimos nosotros- no sólo se vulnera el principio de claridad procedimental, sino que el instructor del procedimiento se arroga una función de investigación del delito que es propia del juez de instrucción, violentándose los derechos que resulta aplicables en las actuaciones de investigación penal que solo podrían resolverse, en parte, en forma de la articulación de un derecho a la no utilización en el proceso penal de las informaciones autoinculpatorias realizadas por el obligado pensando que se encontraba en el procedimiento de regularización de deuda. (Palao Taboada (2013) p. 43 y ss). En esta misma línea nos hemos pronunciado en otro lugar: López Martínez (2016) p. 39 y ss. 40. En este mismo sentido Iglesias Capellas (2013-II-) p. 106. Que señalará, que es a partir de dicho instante, cuando, para preservar la garantías procesales del presunto autor del delito, "la investigación de los hechos debe realizarse de conformidad con lo dispuesto en la Ley de Enjuiciamiento Criminal p. 105. 
al obligado tributario y proceder a la segregación de cuotas, con una nueva naturaleza en lo que concierne a las actuaciones inspectoras tendentes a liquidar la cuota vinculada al delito con la reforma recientemente acaecida en el Reino de España.

Siendo ello cierto, no lo es menos que a los efectos ahora analizados, y en ambos sistemas, no debemos olvidar que entre la «noticia criminis» y la existencia de los indicios suficientemente representativos para paralizar las actuaciones o segregar la cuotas, existe un decalaje temporal en el que de facto se ha mutado la naturaleza del procedimiento de regularización de la deuda sin conocimiento del obligado tributario. Y es, según pensamos, en este preciso momento en el que se ha de materializar el derecho a la información al que venimos haciendo referencia para evitar que en el procedimiento de regularización se conculquen derechos que asisten al imputado en el ejercicio del «Ius puniendi».

La determinación de momento de mutación de la naturaleza de la actuaciones de regularización y de sus efectos, es el primer punto conflictivo -no resuelto en la anterior normativa- que contemplaba el concreto sistema de relaciones entre la instrucción del procedimiento y del proceso ${ }^{41}$ en nuestro derecho positivo. No obstante, como adelantábamos páginas arriba, esta problemática en modo alguno se mejora con la nueva legislación. Y no se resuelve, como decíamos en las ideas previas que servían de contexto necesario para nuestras actuales consideraciones, porque la finalidad de la reforma no era establecer un nuevo sistema de conexión entre procedimiento y proceso más respetuoso con los principios y derechos que se encuentran en juego, sino que su pretensión se limita a configurar una «prejudicialidad fáctica», con exclusivos fines recaudatorios ${ }^{42}$.

41. Obviamente, las actuaciones posteriores a la suspensión de las actuaciones por parte del actuario -bien la remisión del expediente al Delegado especial o central o al Director del departamento correspondiente, bien la orden de completar el expediente con carácter previo a su posible remisión- y los informes posteriores exigidos, forman parte de este subprocedimiento en el que con toda claridad se realizan actuaciones ajenas a las de regularización de la deuda y en la que han de resultar operativos otros deberes y derechos diferenciados que los aplicables en el procedimiento de inspección tributaria.

42. Por utilizar las expresiones contenidas en sus distintas exposiciones de motivos, no paralizar la liquidación -ni la recaudación de la deuda- aunque se traslade el tanto de culpa a la jurisdicción competente «para situar al presunto delincuente en la misma posición que cualquier otro deudor tributario». 
En efecto, si bien se analiza el nuevo sistema que establece que salvo en supuestos tasados la presencia de la «noticia criminis» no paralice las actuaciones de liquidación (ni posteriormente las de recaudación), no implica que en el curso del procedimiento de regularización, el actuario haya encontrado los indicios que suponen la mutación del procedimiento de regularización y que en su seno se obtenga datos y pruebas, en ocasiones utilizando los deberes de información con la amenaza de sanción, que posteriormente van a ser utilizados en la instrucción del proceso de un delito contra la Hacienda Pública. Y si no estamos errados en nuestras consideraciones ello significa que la reforma, lejos de solucionar la problemática estudiada, la obvia, sacralizando la situación fáctica hasta ahora existente - tras la reforma con el consiguiente refrendo legal- pero que sigue perturbando los derechos del futuro imputado. Y ello seguirá produciéndose hasta que en el diseño de las relaciones analizadas se adopten alguna de las siguientes decisiones: bien precisar la obligatoriedad del ejercicio -y su alcance- del deber de información al obligado en el momento en que aparecen los primeros indicios de la existencia de un tipo penal -a partir de dicho momento no deberían de obtenerse datos y pruebas de naturaleza autoincriminatoria con amenaza de sanción- 43 ; bien establecer una clara independencia entre ambas instrucciones - colocándolas en un plano de igualdad- de forma que los datos autoincriminatorios obtenidos en regularización en cumplimientos de los deberes de colaboración, bajo amenaza de sanción, no sean utilizados en la instrucción del proceso; o bien su propia combinación, es decir, determinar la obligatoriedad del derecho a la información de la existencia de la «noticia criminis» y precisar que ante su incumplimiento, no puedan ser utilizados los datos obtenidos bajo la amenaza de sanción.

b. Naturaleza, contenidos y efectos del traslado del tanto de culpa.

Para llevar a buen puerto nuestras actuales consideraciones, en la línea que manteníamos en los epígrafes anteriores, hemos de comenzar señalando que existe consenso en nuestra doctrina procesal en definir al «tanto de culpa» como aquél acto emitido por un órgano administrativo o judicial -y remitido al juez penal- en el que se contiene la noticia de la comisión de un hecho delictivo conocido en el desempeño de

43. En el sentido y con el alcance que analizaremos en otro momento del presente trabajo. 
sus funciones ${ }^{44}$. En consecuencia, "precisamente por la singular naturaleza de su emisor, el «tanto de culpa» se configura como una denuncia cualificada que, por ministerio de la ley, debe revestir mayores garantías de certeza y de veracidad que la denuncia" que se encuentra al alcance de cualquier ciudadano ${ }^{45}$.

Siendo ello cierto, como hemos desarrollado en otro lugar ${ }^{46}$, no lo es menos que en el análisis de las conexiones entre la instrucción del procedimiento de regularización y el proceso por delito contra la Hacienda Pública, las propias garantías de certeza y veracidad que han de caracterizar al correspondiente traslado del «tanto de culpa» y que justificaban la propia existencia del subprocedimiento administrativo previo a su remisión, corren el riesgo de convertirse, en la verdadera instrucción que ha de realizarse con posterioridad, en sede penal ${ }^{47}$. Este hecho se complica exponencialmente tras la entrada en vigor de la nueva normativa tributaria en la que se permite que continúen las actuaciones de regularización hasta liquidar la cuota vinculada al delito. Estamos ante otro de los problemas esenciales que, a nuestro juicio, no se encuentra resuelto lege data en la articulación de las conexiones entre la regularización tributaria y la instrucción del proceso por delito frente a la Hacienda Pública y que de facto ocasiona la lesión de los derechos y garantías del obligado tributario en su posición de imputado.

Para justificar cuanto antecede, hemos de tener en cuenta que la remisión del denominado «tanto de culpa» incorpora un contenido mínimo que se encuentra reglado en nuestra normativa, ya que dicha comunicación deberá ir acompañada de todos los elementos probatorios que se han obtenido en el procedimiento de regularización tributaria a los que se le incorporaran el conjunto de informes de los

44. Se trata en consecuencia de un acto de comunicación de una noticia delictiva realizado por aquél órgano que en el ejercicio de sus funciones tiene conocimiento de un hecho de apariencia delictiva y lo pone en conocimiento del juez penal que resulte competente. Nos encontramos ante una especie de denuncia presentada ante el juez penal, especialmente cualificada, por la naturaleza de su emisor. En este sentido ver, entre otros a Torres Rosell (1991) p. 438 y ss.

45. Iglesias Capellas (2013-II-) p. 111.

46. López Martínez (2016).

47. Y ello, por mucho que la doctrina que se ha ocupado del tema, señale con toda claridad que los datos y pruebas aportada por la Administración tributaria y que constituyen el contenido del «tanto de culpa», no han de vincular al juez instructor "que ha de ordenar la práctica de cuantas diligencias resulten necesarias para la averiguación de los hechos denunciados" (Iglesias Capellas (2013-II-) p. 111). 
diferentes órganos previstos por la normativa tributaria ${ }^{48}$. Y por esta razón, a los efectos del presente trabajo conviene precisar el contenido -y su alcance en la instrucción penal- de los datos que han de ser trasladados a la Jurisdicción desde los órganos competentes de la Administración tributaria, ya que el «tanto de culpa» se configurará, a estos efectos, como el acto de comunicación de la «noticia criminis», con plenos efectos y consecuencias procesales 49 .

48. Art.32.2 « Cuando la circunstancia prevista en el apartado anterior se aprecie antes de la propuesta de liquidación, el órgano, equipo o unidad remitirá las actuaciones practicadas con las diligencias en las que consten los hechos y circunstancias que, a su juicio, determinan la posible responsabilidad penal y un informe preceptivo sobre la presunta concurrencia en los hechos de los elementos constitutivos del delito al jefe del órgano administrativo competente, por medio de su superior jerárquico.

Cuando la apreciación tenga lugar después de la propuesta de liquidación, será el órgano competente para liquidar quien debe proceder a impulsar el procedimiento, previa elaboración del preceptivo informe. Cuando dicha apreciación se produzca durante la tramitación del procedimiento sancionador, y los actos de liquidación ya hayan sido dictados, el órgano, equipo o unidad que instruya dicho procedimiento suspenderá su tramitación y trasladará las actuaciones de comprobación y las del procedimiento sancionador, junto con el correspondiente informe, al jefe del órgano administrativo competente, por medio de su superior jerárquico. Asimismo, se suspenderá la ejecución de la liquidación hasta que recaiga la correspondiente resolución judicial. A efectos de lo dispuesto en este artículo, se entenderá por órgano administrativo competente el que, según la normativa de organización aplicable, tenga atribuidas las funciones de apreciación de la existencia de hechos constitutivos de delito contra la Hacienda pública. En los procedimientos de inspección, el jefe del órgano administrativo competente será el inspector-jefe correspondiente.»

3. «A la vista de la documentación recibida y de los informes que haya considerado oportuno solicitar, el jefe del órgano administrativo competente, si aprecia la existencia de un posible delito, deberá remitir el expediente al delegado especial o central o al director del departamento correspondiente, según de quien dependa el órgano actuante. El jefe del órgano administrativo competente podrá ordenar completar el expediente con carácter previo a decidir sobre su remisión o no al delegado o al director del departamento correspondiente.

Si el jefe del órgano administrativo competente no aprecia la existencia de un posible delito devolverá el expediente al órgano que se lo hubiera remitido o a otro distinto para que lo ultime en vía administrativa». 4. «Una vez recibida la documentación, el delegado o el director de departamento competente acordará, previo informe del órgano con funciones de asesoramiento jurídico, la remisión del expediente a la jurisdicción competente o al Ministerio Fiscal, o la devolución del mismo, según aprecie o no la posible existencia de delito». 49. Iglesias Capellas (2013-II-) p. 112 y 113. Lo que no significa - continúa indicando el citado autor- "que de ello pueda concluirse que la Administración tributaria este ejerciendo la función de acusador particular sino que, sin perjuicio de que, una vez iniciado el proceso, pueda llegar a ostentar la condición de víctima o perjudicada por el acto delictivo, deja de ser el juez penal quien traslade los hechos al Ministerio Fiscal (en su condición de acusador público) y determine o no si procede o no iniciar el proceso penal". 
Si atendemos a la situación previa a la entrada en vigor de la actual normativa, en primer lugar, el contenido del «tanto de culpa» estará compuesto por los propios elementos probatorios obtenidos en el curso de las actuaciones inspectoras, en consecuencia, obtenidos a través de unas potestades y funciones de corte exclusivamente regularizador de deudas. No obstante, a los efectos de preservar los derechos y garantías del obligado en este tránsito de las pruebas del regularizador al proceso, conviene que diferenciemos, dentro de este primer grupo ${ }^{50}$, aquellos datos obtenidos antes y después de que el actuario observara los primeros indicios de la existencia de un ilícito que pudiera ser constitutivo de un delito contra la Hacienda Pública. Y también conviene que tengamos presente en nuestras consideraciones, como adelantamos líneas arriba, que la naturaleza, alcance y la propia licitud del contenido de las pruebas trasladadas, dependerán de que se haya efectuado, o no, y de forma tempestiva, el derecho a la información de la mutación de las actuaciones inspectoras ${ }^{51}$.

En segundo lugar, de nuevo con la anterior normativa, formará parte del contenido típico del oficio de remisión del «tanto de culpa», los datos y pruebas que han sido obtenidas en las actuaciones propias del subprocedimiento previsto para tomar la decisión de elevar, o no, el «tanto de culpa» a la Jurisdicción competente ${ }^{52}$.

Estas actuaciones, como también hemos anticipado ${ }^{53}$, resultan claramente ajenas a la regularización de la deuda y en consecuencia, en su desarrollo se han de observar los derechos y garantías propias del «Ius puniendi estatal», de forma que su valor en el proceso dependerá que se haya adecuado a su fin las actuaciones seguidas en esta fase procedimental.

50. Elementos probatorios obtenidos en sede de regularización.

51. Por último, para realizar un análisis completo de las implicaciones de los datos y pruebas aportados del procedimiento de regularización al proceso, no hemos de olvidar que la propia normativa nos indica que en el oficio de remisión del «tanto de culpa» se han de incorporar cuantas diligencias -y en su caso actas- se hubiesen formulado, lo que no resulta baladí, como resulta plenamente conocido, a efectos de determinar el valor probatorio de los datos incorporados en estos documentos públicos.

52. Por ejemplo, aquellas que puede ordenar el propio inspector jefe, antes de remitir el expediente al Delegado o al Director del departamento competente. Estas actuaciones, si bien tienen por finalidad completar el expediente, éste, no es ya el de regularización, sino que ha de tener por objeto exclusivo la consolidación de los indicios suficientes como para proseguir este procedimiento, a efectos de paralizar las actuaciones inspectoras.

53. López Martínez (2016). 
Por último, el contenido del denominado «tanto de culpa», se cerraba con la remisión del conjunto de informes que han de emitir los diferentes órganos previstos en el subprocedimiento analizado ${ }^{54}$, cuyo contenido -y sus efectoshan de limitarse a formar la opinión del juez que resulte competente para que proceda al inicio del proceso penal o devuelva al expediente al órgano denunciante ${ }^{55}$.

Teniendo en cuenta cuanto antecede, el análisis que debía de realizarse, no ha de consistir, exclusivamente, en el estudio del diferente alcance de la prueba y de la carga de la prueba obtenida en el procedimiento regularizador en la instrucción de un proceso penal, que evidentemente se trata de un tema esencial para aquilatar los derechos y las garantías que han de ser operativos en el procedimiento y en el proceso, sino que junto al ello, y a nuestro juicio con carácter previo, se debería de analizar la diferenciada procedencia de los datos incorporados en el oficio de remisión del «tanto de culpa», cuestión que ha de ser tenida en cuenta en la instrucción del proceso que estos datos trasladados no puede suplantar.

Desde esta perspectiva, hemos de señalar que la reforma incorporada en la legislación española, tampoco se ocupa de regular con precisión el diferente alcance de las pruebas que van a ser trasladadas, ya que la única novedad -si lo fuera-56 , es que el traslado del «tanto de culpa» se efectuará una vez que se haya dictado la liquidación vinculada al delito, puesto que el procedimiento de regularización no se paraliza por la existencia de la «noticia criminis». En consecuencia, al conjunto de elementos que debemos de analizar para que la articulación de las relaciones entre ambas instrucciones se rija por los principios y garantías exigibles, es decir, al contenido antes indicado, habrá que añadirle

54. 1으) El informe de la unidad o equipo responsable de la comprobación; $2^{\circ}$ ) El informe de la Unidad del delito Fiscal; 3ํㅜ) El informe de los órganos consultivos.

55. En esta misma línea de consideraciones conviene no olvidar que la propia normativa prevé la opción de elevar el correspondiente tanto de culpa como instrumento formal para promover la acción penal, o proceder a la remisión del expediente al Ministerio Fiscal. Y esta opción no resulta neutral desde el punto de vista de las consecuencias procesales. Para un desarrollo de dichas consecuencias ver entre otros a Iglesias Capellas. (2013-II-) p. 113 y ss. Y Ruiz García (2011) p. 741 y ss.

56. A estos efectos conviene recordar que el traslado del «tanto de culpa» en la legislación derogada, también podía realizarse una vez terminado el procedimiento de regularización tributaria. 
el propio acto administrativo de liquidación ${ }^{57}$. Y sobre este, hemos de convenir con Ruiz García, en que el acto administrativo de liquidación, a diferencia de las diligencias y las actas que son catalogados legalmente como documentos públicos -arts.107.1 y 144.1 LGT- a efectos probatorios, "no es un simple medio de prueba, sino un acto resolutorio -art. 101.1 LGT-. Y en esta condición, el acto de liquidación incorporará una valoración, explícita o implícita, de los medios de prueba que obren en el expediente, y que aparecerá reflejados en las diligencias y en el acta"58. Pero nada más. Nada se resuelve en la nueva legislación, sobre el alcance de los datos y las pruebas que configuran el contenido del oficio del traslado del «tanto de culpa»; y, nada, sobre la llamada cuestión prejudicial tributaria, que sigue ordenando al instructor penal -en cumplimiento de lo estipulado en el art. 7 del la Ley de Enjuiciamiento Criminal- que se apliquen las reglas del derecho tributario, pero siempre de conformidad de las reglas de valoración de la prueba propias de la instrucción penal ${ }^{59}$.

Ello significa, a nuestro juicio, que la problemática que en torno a las relaciones entre regularización y proceso se deriva del traslado de datos y pruebas de una al otro, no sólo ha de estudiarse teniendo en cuenta los diferentes momentos en los que los datos han sido obtenidos, sino considerando, igualmente, la necesidad de separar nítidamente el aspecto sustantivo y procesal que se plantean en las relaciones analizadas: «en el primero, el juez penal ha de ajustarse a la normativa fiscal60; en el segundo, ha de someterse de modo estricto, como en cualquier otra materia, a las normas y jurisprudencia que regulan los requisitos de la prueba para

57. «que al incorporarse en el procedo penal por delito fiscal no será otra cosa que una prueba más, sin duda atendible, pero en todo caso sometida al pertinente debate entre las partes y a la posterior valoración del tribunal» STS 3.IV.2003 -FJ 15o-, que reproduce la indicado por la S 2069/2002, de 5 de Diciembre. 58. "Lo que la jurisprudencia citada quiere expresar es que el juez penal no está vinculado a la valoración de la prueba efectuada en el acto de liquidación” Ruiz García (2011) p. 754. Y en consecuencia, también desde esta perspectiva, el instructor penal deberá diferenciar claramente en la información trasladada del regularizador, "el contenido «fáctico» o documental, que tiene por finalidad principal acreditar el descubrimiento de un hecho imponible no declarado o declarado de forma incompleta o inexacta, y un contenido «jurídico» o valorativo, que se corresponde con la apreciación de la trascendencia penal de la conducta del obligado tributario"; Iglesias Capellas (2013) p. 133.

59. Ver, entre otras muchas las SSTS de 5.XI. 2002 y 3.IV.2003.

60. Recordemos, una vez más, que gran parte de esta problemática obedece a la configuración del tipo del delito contra la Hacienda Pública. 
que se puedan considerar de cargo y servir de fundamento a una condena penal»61 .

\begin{abstract}
Como consecuencia de todo cuanto antecede, el aspecto más relevante del traslado de datos y pruebas del regularizador al proceso, consiste en que la utilización de estos datos o pruebas no suplante la instrucción del proceso penal en la que habrá que destruir la presunción de inocencia ${ }^{62}$. Y habrá que hacerlo teniendo en cuenta el «contenido esencial» del meritado principio63.
\end{abstract}

61. STS. 16.V.2002. Y a estos efectos conviene tener en cuenta, como señalamos en otro momento del presente trabajo, que la aplicación de las reglas de la prueba y de la carga de la prueba en la instrucción del proceso penal, son incompatibles con algunas reglas de valoración, estimaciones o presunciones utilizadas en el procedimiento tributario, por mucho que éstas últimas hayan sido trasladadas a la instrucción del proceso, e incorporadas en diligencias, actas o en el propio acto de liquidación tributario previo al paso del «tanto de culpa». 62. Como hemos indicado en otro lugar, los caracteres de la presunción de inocencia pueden quedar esquematizados con las siguientes notas: en primer lugar es un derecho fundamental por cuya virtud "una persona acusada de una infracción no puede ser considerada culpable hasta que así se declare en Sentencia condenatoria, siendo sólo admisible y lícita esta condena cuando haya mediado actividad probatoria que, producida con las garantías procesales y libremente valorada por los Tribunales penales, pueda entenderse de cargo" (STC137/ 1988, de 7 de julio.J.F. Io); en segundo término es un derecho público subjetivo, que en consecuencia opera tanto procesal como extraprocesalmente; en tercer lugar, su ámbito fundamental de actuación se ha de concentrar en el terreno de la prueba necesaria para desvirtuar la presunción ínsita en el principio, encontrando, desde el punto de vista constitucional, sus principales problemas a la hora de separar el control constitucional de la misma, de la valoración judicial, tanto de la existencia, como del contenido y de la calificación jurídica de la prueba, que en principio corresponden en exclusiva a los Tribunales de Justicia; por último, aunque comparta con el principio jurisprudencial "in dubio pro reo", el ser ambas manifestaciones del principio favor rei, conviene, para determinar su real alcance y contenido, precisar su diferencia esencial que consiste en observar como la presunción de inocencia desenvuelve su eficacia cuando existe una falta absoluta de pruebas, o las practicadas no reúnen las garantías procesales, mientras que el principio in dubio pro reo, pertenece al momento de la valoración o apreciación probatoria, cuando existe una duda razonable sobre la real coincidencia entre los elementos objetivos y subjetivos que se integran en el tipo(STC 44/1989, de 20 de febrero. F. J. IIo). López Martínez (2003) p. 484 y ss.

63. Que ha de quedar estructurado en relación a las siguientes ideas: 1ํ. Una persona no puede ser declarada culpable hasta que no exista sentencia condenatoria. $2^{\circ}$. La condena sólo es constitucionalmente lícita si ha mediado actividad probatoria de cargo. $3^{\circ}$. La actividad probatoria ha de desarrollarse con todas las garantías

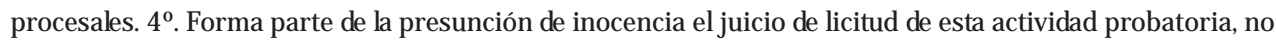

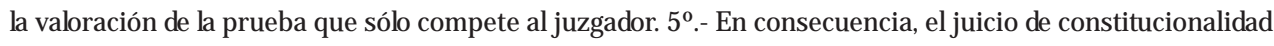
ha de realizarse sobre las características necesarias que han de tener las pruebas para desvirtuar la presunción de inocencia. 60 Las indicadas características pueden quedar sintetizadas como siguen: a) su existencia; b) a cargo de la acusación; c) su motivación; d) su suficiencia; e) que se hayan sometido al principio contradictorio que impide la prueba diabólica; f) que sea pública y se practique en juicio oral, salvo la preconstituidas o anticipadas que no 
En este orden de consideraciones, resulta conveniente comenzar señalando que en ocasiones se tiende a olvidar cual es la propia función que desarrolla el instituto jurídico de la prueba ${ }^{64}$. Y conviene igualmente tener constantemente presente que lo «probado» en vía de regularización, e incorporado en el oficio de remisión del pertinente «tanto de culpa», no ha de trascender de sus efectos típicos, que no son otros que formar la opinión de juez competente para que ordene la apertura o no de un procedimiento por delito fiscal65. Lo anterior, no significa que en la instrucción del proceso no se tengan en cuenta estos datos y pruebas, pero han de hacerse en función del valor que han de ostentar en el seno del proceso penal. Y ello, a pesar de que dichos datos y pruebas hayan sido incorporadas en las correspondientes actas y diligenciasen su condición de documentos públicos. Ya la STC 76/1990, tuvo ocasión de abrir la línea de interpretación constitucional sobre la cuestión analizada66, presentándonos,

pueden reproducirse en el mismo, y siempre que en su obtención se haya garantizado la contradicción y la publicidad; g) que de tratarse de prueba de indicios ha de haber prueba clara de los mismos y ha de explicitarse un razonamiento de la derivación de éstos hacia el convencimiento de la culpabilidad. (López Martínez (2003) p. 484 y ss.). 64. Que sirve para vislumbrar en qué medida el mecanismo mental y operativo, consustancial a aquélla, se proyecta en el acaecimiento puntual de las realidades jurídicas, ámbito este en que la prueba se encuentra categorizada como noción de la Teoría General del Derecho. López Molino (1998) p. 47. 65. Se ha de llamar la atención sobre que hablamos de concepto prueba, no de la valoración de la misma, que como hemos indicado en otro lugar -López Martínez (2003) p. 484 y ss.- se ha de diferenciar desde la óptica de la presunción de inocencia, puesto que ésta desenvuelve su eficacia cuando existe una falta absoluta de pruebas, o las practicadas no reúnen las garantías procesales, mientras que el principio in dubio pro reo, pertenece al momento de la valoración o apreciación probatoria, cuando existe una duda razonable sobre la real coincidencia entre los elementos objetivos y subjetivos que se integran en el tipo. 66. Los problemas a enjuiciar han de centrase en el estudio de dos suertes de consideraciones: "En esa dirección, las cuestiones atinentes al caso a las que debemos dar respuesta son las dos siguientes: 1. a , si las actas y diligencias extendidas por la Inspección de Tributos merecen o no la consideración de medio de prueba admisible en Derecho, y 2. ${ }^{\text {a }}$, si la eficacia que el art. 144.3 de la LGT otorga a tales actas y diligencias es o no compatible con el derecho a la presunción de inocencia que a todos reconoce el art. 24.2 de la Constitución” -F. J. VIII -de la STC 76/ 1990, de 26 de abril. Y a este respecto de su fundamentos jurídicos podemos extraer las siguientes consideraciones: «1ạ.- Que no hay ningún obstáculo para considerar las actas y diligencias extendidas por la Inspección de los Tributos, como medio de prueba; 2 a- - Que las actas y diligencias mencionadas constituyen un primer elemento de prueba sobre los hechos que constatan, cuyo valor y eficacia ha de medirse a la luz del principio de libre valoración de la prueba; 3ạ.- El valor probatorio de estos documentos públicos sólo puede referirse a los hechos comprobados directamente por el funcionario, quedando fuera de su alcance la calificaciones jurídicas; $4 \stackrel{a}{a}$-Las actas y las diligencias mencionadas pueden servir para destruir la presunciones de inocencia, sin necesidad de reiterar en vía judicial la actividad probatoria de cargo practicada en el expediente administrativo». 
de forma nítida su postura al indicar que "no es admisible que el proceso penal pueda resultar condicionado por una presunción previa derivada del procedimiento administrativo de inspección y comprobación de la situación tributaria del contribuyente, pues ello significaría que la documentación de la Inspección tendría a efectos penales un valor de certeza de los hechos que en la misma se hacen constar, viniendo obligado el pretendido infractor a destruir aquella certeza mediante la prueba en contrario de su inocencia" 67.

En consecuencia, la incorporación de datos analizada, si bien puede actuar como prueba preconstituída 68 , si se refiere a los hechos probados por el funcionario, no asus juicios de valor ni a sus repercusiones jurídicas ${ }^{69}$, se deben considerar como un primer elemento probatorio que ha de medirse a la luz del principio de libre valoración de la prueba ${ }^{70}$. No obstante, la prueba, no sólo ha de existir, ha de ser motivada71, y, además, ha de ser suficiente.

Pero es más, la exigencia de la suficiencia de la prueba, para la destrucción de la presunción de inocencia, ha de serlo en relación a los hechos y en relación a la culpabilidad:

En lo que hace referencia a los hechos, hemos de recordar que el principio de presunción de inocencia exige que sea lícita la actividad probatoria de cargo, y que ésta se realice con todas las garantías procesales, lo cual, si bien no interfiere con la valoración de la prueba, que sólo compete al juzgador, sí exige un juicio previo sobre su licitud ${ }^{72}$. De las múltiples implicaciones que podíamos

67. FJ. VIII $\mathrm{o}$ de la STC 76/ 1990, de 26 de abril.

68. Fuster Asencio (2001) p. 252.

69. Polo Soriano (1986) p. 56.

70. Lo cual significa, "que la presunción legal de certeza que ostentan los hechos recogidos en las actas y las diligencias no sólo puede ser destruida por otros medios de prueba sino que queda a la libre apreciación de los Tribunales, es decir, que el juzgador puede rechazarla como prueba sin necesidad de que se haya probado lo contrario a lo recogido en acta o diligencia". Siles Cantero (1995) p. 59.

71. Sin que la simple constatación de hechos en las actas o diligencias inspectoras, sin más soporte que la declaración del funcionario que los consigna, tenga la eficacia plena probatoria.

72. Y aquí es donde hemos de tener presente las consideraciones realizadas líneas arriba sobre el ejercicio al derecho a la información tras la aparición de la «noticia criminis» y sobre el diverso contenido y alcance de los datos e informes incorporados en el oficio del traslado de correspondiente «tanto de culpa». 
poner de manifiesto, a los efectos del presente trabajo ${ }^{73}$ baste aludir a dos de las que consideramos más representativas: las que hacen referencia al derecho de no autoinculpación y las que atienden a la licitud de las pruebas obtenidas en el procedimiento de regularización en base a los propios datos aportados bajo la amenaza de sanción.

En relación a la primera de las cuestiones indicadas, debemos realizar una remisión a cuanto señalaremos con posterioridad para precisar qué datos hemos de excluir entre los aportados por el sujeto en cumplimiento de deberes de colaboración bajo la amenaza de sanción. Más problemático resulta determinar el alcance del resto de los datos obtenidos en regularización, ya que un sector importante de nuestra doctrina, considera, que todo el procedimiento de regularización se encuentra impregnado por el cumplimiento del deber de colaborar $^{74}$. Parece evidente que este problema incide en la línea de flotación de la temática ahora abordada, puesto que de resultar operativa la indicada tesis, difícilmente serían lícitas las pruebas aportadas a la instrucción penal75.

73. Para un análisis más detenido de cuanto aquí simplemente dejamos anotado ver entre otros a Iglesias Capellas (2013) p. 13 y ss.

74. Puesto que la doctrina de bs "frutos del árbol envenenado" (fruits of the poisoned tree doctrine), no alcanza sób a "los datosy pruebas suministradas directamentepor el contribuyente (en cumplimiento del deber de colaborar en la inspección, y por tanto con infracción del derecho a guardar silencio), sino también a otros materiales probatorios conexos, que se basen, apoyen o deriven de modo directo o indirecto dela prueba ilícita -ya que-..aunqueen el expedientedela inspección pudieran existir < <pruebasdiferentes > a las obtenidasen cumplimiento del deber decolaboración del contribuyente, difícilmente se trataría de <ৎpruebasindependientes >” FALOÓNYTELLA(1998) p.491 y 492.

75. Aunque hemos deindicar que la doctrina procesalistay lajurisprudenciavertidaal respecto, suele no derivar dela expresión "directa o indirectamente", referenciada en el art.11 LOPJ, a la doctrina de bs "frutos del árbol envenenado" en relación al resto de las piezas de convicción obtenidas por la Inspección de los Tributos, que pueden originarse de las declaraciones autoinculpatorias del obligado Díaz-Palacio Sanz (2002) p.46y ss. En este sentido González Montes (1990) p.39y ss, considera que el legislador no ha querido consagrar en el precepto de referencia dicha doctrina, sino que cuando se ahude a las infraociones directas se hacen referencia a las que se producen dentro del proceso (en la admisión y práctica de la prueba), siendo infracciones directas aquéllas que se producen fuera del mismo (en la búsqueda y recogida de las fuentes de prueba). Y en esta misma línea de planteamiento, RODRÍGUEZ SOL (1998) p.81, señala que hay que distinguir, con toda claridad los arts. 11.1 y $238.3^{0}$ de la LOPJ, ya que ambos preceptos se refieren a supuestos claramente diferenciables, de forma que el último precepto citado se aplicaría ante la violación de los derechos fundamentales de carácter procesal consagrados en el art. 24 de la Constitución, mientras que el primero hace referencia a la vulneración de bs restantes derechos fundamentales. Y ello supone, puesto que el art. 238.3ํㅡ no contempla el efecto invalidante de la prueba relacionada con un acto judicial nub, que en materia tributaria, y a los efectos analizados, carecerían de eficacia probatoria los datos autoincriminatorios, pero no bs que hubiera podido obtener la Inspección a partir de los mismos Díaz-Palacio Sanz (2002) p.51. 
Hemos de tener en cuenta que aunque fuese operativa la indicada teoría en nuestro Ordenamiento ${ }^{76}$, esta doctrina exige la concurrencia de dos requisitos: en primer lugar, la ilicitud de la prueba debe obedecer a la vulneración de un derecho fundamental sustantivo o a una "regla básica de todos los procedimientos de la democracia"; en segundo término, la contaminación de las pruebas obtenidas a partir de la actuación probatoria ilícita sólo se produce cuando entre éstas y las pruebas lícitamente obtenidas existe un nexo que imposibilite la obtención de las segundas sin la concurrencia de las primeras ${ }^{77}$. No obstante, a los efectos de su operatividad en nuestro actual objeto de estudio, henos de señalar que las pruebas obtenidas en regularización son perfectamente lícitas, como lícitos son los deberes de colaboración en su seno. De manera que resultaría de muy difícil aplicación la "reconversión" de pruebas lícitamente obtenidas, en una prueba contaminada, por su simple incorporación a la instrucción del procedimiento, teniendo en cuenta además, que no son directamente autoinculpatorias. En consecuencia, y a pesar del valor probatorio que puedan tener los datos y las pruebas aportados, su suficiencia en relación a los aspectos fácticos, va a depender 78, de la estructura de investigación llevada a cabo en el procedimiento de regularización.

Junto a lo anterior, como indicábamos, se ha de abordar la cuestión de la prueba de la culpabilidad, como elementos configuradores del tipo, ya que como ha señalado nuestro Tribunal Supremo "no es el interesado quien ha de probar la falta de culpabilidad, sino que ha de ser la Administración sancionadora la que demuestre la ausencia de diligencia"79. En consecuencia, por mandato constitucional, corresponde a la Administración tributaria, o a la Jurisdicción competente, la prueba de la concurrencia de las circunstancias que determinan la culpabilidad del infractor en la comisión del ilícito tributario y en la prueba de dichos aspectos se ha de poner el mismo empeño que en la de los elementos de hecho del tipo, sin que pueda acreditarse en base a simples conjeturas, ni con un acentuado automatismo, como lamentablemente ocurre en la actualidad, sino con la misma intensidad y técnica probatoria sobre la que se construye la prueba fáctica ${ }^{80}$.

76. Miranda Estrampes (1999) p. 108 y ss. y Martin Queralt (1998) p. 3 y ss.

77. Caamaño Anido (2002) p. 116.

78. Además de cuanto significamos líneas arriba en relación al ejercicio tempestivo del derecho a la información y al diverso contenido y momento en el que se traslada el «tanto de culpa».

79. STS de 5 de noviembre de 1998 (RA 7945).

80. López Martínez (2001-I-) p.500 y (2001 -II-) p. 92. 
En este mismo orden de consideraciones que también hemos abordado en otro lugar81, debemos dejar anotado, mínimamente, que sobre esta problemática incide, también, la conformidad o disconformidad a los datos y pruebas prestada en sede de regularización y trasladados a la instrucción del proceso penal ${ }^{82}$. Centrándonos en sus implicaciones con el derecho a ser informado de la acusación, y puesto que al prestar la conformidad a los datos fácticos consignados en el acta, se debilitan tanto los derechos a la defensa, como la propia presunción de inocencia ${ }^{83}$, hemos de recordar cuanto más arriba indicábamos al señalar que en sede de regularización, se debería advertir de tal hecho, con anterioridad a la firma del acta, puesto que como hemos significado, el derecho a ser informado, ha de realizarse con carácter tempestivo, y en consecuencia, con carácter previo a cualquier actuación que pueda resultar autoincriminatoria 84 .

a. Operatividad y limites del derecho a no autoinculparse en el procedimiento regularizador de deudas.

Resulta evidente que por la propia estructura del presente trabajo, el analisis que nos proponemos realizar sobre la operatividad del derecho a no autoinculparse en el procedimiento de regularización, no pretende realizar un estudio detenido del conjunto de implicaciones que este derecho ha suscitado en nuestra doctrina y en nuestra jurispridencia ${ }^{85}$, nuestra pretensión es mucho más modesta, nos limitaremos a conectar el alcance de dicho derecho como punto nuclear de la articulación de las relaciones entre regularización

81. López Martínez (2016).

82. Puesto que dicha materia afectará, al menos, a la tutela judicial efectiva, a la presunción de inocencia, a los derechos de defensa -especialmente al derecho a ser informado de la acusación- y derecho a no autoinculparse.

83. Navarro Egea(2001) p. 13 y ss.

84. Aneiros Pereira (2002) p. 17.

85. Voces más autorizadas que la de quien suscribe han realizado brillantes estudios sobre su alcance y contenido. Para un análisis de la doctrina y la jurisprudencia sobre la operatividad de dicho principio, nos remitimos, además de a los incorporados en la bibliografía que cierra el presente estudio, a la que henos incorporado en otros trabajos que hemos tenido la oportunidad de realizar. Por todos, López Martínez,J. (2003) p. 376 y ss. En esta misma línea es especialmente interesante el trabajo de Rubio Montiel (2012) p. 5 y ss. En esta misma línea de planteamiento López Martínez (2016). 
y proceso 86 . No obstante, a los efectos de llevar a buen puerto nuestras pretensiones, si deberíamos acotar el contenido esencial del indicado derecho $\mathrm{y}$, para ello ${ }^{87}$, conviene comenzar indicando que los derechos a no confesarse culpable y a no declarar contra sí mismo han encontrado su origen en nuestra doctrina como sendas manifestaciones del derecho a la defensa en la lucha por un proceso penal público, acusatorio, contradictorio y con todas las garantías, que se inicia en la Europa continental en la segunda mitad del siglo XVIII, frente al viejo proceso penal inquisitivo ${ }^{88}$.

Es en el contexto de ambos principios, derecho a la defensa y presunción de inocencia, y en su interrelación con el conjunto de garantías que han de entrar en juego, dónde hemos de localizar el contenido esencial de los meritados derechos, que podemos sintetizar con nuestro máximo Intérprete-por todas, STC161/ 1997con los siguientes puntos:

En primer término, como resulta conocido, dicho contenido alcanza a la interdicción de "la compulsión del testimonio contra uno mismo", es decir, únicamente prohíbe condenar o sancionar a un sujeto con el fundamento a la información aportada por éste bajo sanción ${ }^{89}$. Sin embargo, el problema radica en que en

86. En efecto, el verdadero sentido de la operatividad de dicho principio del «Ius puniendi» en el regularizador tributario, no es la mixtura conceptual de los principios que han de aplicarse en los diferentes procedimientos, sino, precisamente, el trasvase de datos entre las dos instruciones, el contenido que hemos analizado del oficio de remisión del «tanto de culpa» y, el valor y el alcance, de estos datos y pruebas obtenidos en los procedimientos de aplicación de los tributos en la instrucción del proceso por delito fiscal al que hemos hecho referencia páginas arriba.

87. Nos remitimos in extenso a las consideraciones de realizamos en otros trabajos, por todos, López Martínez (2003). 88. Y así lo ha venido declarando nuestro Tribunal Constitucional, que considera tanto al derecho a no prestar declaración en contra de sí mismo, como al derecho a no confesarse culpable, como garantías o derechos instrumentales del genérico derecho a la defensa. No obstante, como adelantábamos, para el cabal entendimiento del contenido esencial de estos derechos hemos de tener presente que los mismos "entroncan también con una de las manifestaciones del derecho a la presunción de inocencia: La que sitúa en la acusación la carga de la prueba". FJ. №. de la STC161/ 1997, de 2 de Octubre.

89. Vid. En este sentido, entre otras las Ss.TC 170/ 1990; 24/ 1992; 172/ 1992. En consecuencia, cuando los datos incriminatorios sean aportados voluntariamente, no es posible deducir de tal conducta una violación del art. 24.2 CE, puesto que como ha reiterado la jurisprudencia del Tribunal Constitucional, a diferencia de otros derechos fundamentales, el derecho a no autoinculparse tiene un carácter renunciable. (STC 170/ 1990, de 5 de noviembre. FJ. Vo). En el mismo sentido, se puede consultar entre otras muchas las SsTC 36/ 1983; 103/ 1985; 22/ 1985; 24/ 1992 y 172/ 1992. 
numerosas ocasiones, no resulta fácil determinar cuando la información se ha facilitado voluntariamente y cuando se ha realizado mediante coacción ${ }^{90}$. A estos efectos, tal y como adelantábamos, creemos que resulta exigible desde la perspectiva constitucional, que en el procedimiento de regularización, y en el marco del derecho a ser informado de la acusación, se advierta de la posibilidad de que los datos voluntariamente facilitados al órgano administrativo podrán incorporarse al hipotético proceso punitivo que puede abrirse con posterioridad.

En segundo lugar, no sólo se requiere la existencia de coacción, sino que las informaciones afecten exclusivamente "a las contribuciones que tienen un contenido directamente incriminatorio". Y en consecuencia, los indicados derechos, no podrán ser alegados para "sustraerse a las diligencias de prevención, de indagación o de prueba que proponga la acusación o que puedan disponer las autoridades judiciales o administrativas ${ }^{91}$.

Por último, ha de tratarse de "contribuciones", es decir, los derechos sólo son constitucionalmente exigibles cuando la información incriminatoria haya sido aportada por el imputado, y no es lo mismo, "aportar" que "soportar prueba" 92. No obstante, una cuestión, conectada con la anterior, consiste en precisar si cuando el Tribunal Constitucional, por ejemplo en su Sentencia 161/ 1997, señala,

90. Por ello, coincidimos con los profesores Aguallo Avilés y García Berro (2000) p. 95 y ss., en considerar que debe presumirse que existe voluntariedad si no existe una reacción sancionadora ante su incumplimiento, y que no la hay, en caso contrario, de forma que, fundamentalmente en materia tributaria corresponderá a la Administración la prueba de la voluntad del sujeto de colaborar por encina de las exigencias legales. 91. Para su desarrollo, in extenso, López Martínez (2003). Lo que significa, a efectos del presente trabajo, que enjuicia las relaciones entre procedimiento y proceso, que los datos exigidos en los procedimientos administrativos para la regularización de la deuda - excluida la sanción-, no pueden ser amparados por el meritado principio. Ello ha de significar, igualmente, que la información ha de ser útil para fundamentar una pena o sanción administrativa y, en consecuencia, que no basta con que los datos solicitados coactivamente puedan causar cualquier perjuicio. Por último, lo anterior también significa que la información aportada ha de ser sea útil para incriminar a quien la suministra, es decir, ha de ser auto-incriminatoria. 92. Herrera Molina (1997) p. 141 y ss. Y por tal hecho, tanto lajurisprudencia de nuestro Tribunal Constitucional, como la del TEDH, han señalado que en principio, los controles de alcoholemia, el reconocimiento en rueda o las intervenciones corporales (extracción de orina, pelo o sangre...) no contradicen los derechos recogidos en los arts. 24.2 CE y 6 CEDH, puesto que en tales supuestos no se exige de los sujetos afectados una "declaración de voluntad" o una "declaración que exteriorice un contenido de admisión de la culpabilidad" STC, 103/ 1985, de 4 de octubre. F.J. IIIํ). 
precisando el ámbito objetivo de los estudiados principios, que "el acusado no tiene el deber de aportar elementos de prueba incriminatorios", este deber de aportar alude a cualquiera de los medios empleados, o se limita a la declaración verbal: ¿es posible alegar los derechos del art.24.2 de la Constitución Española cuando se solicitan documentos incriminatorios con amenaza de sanción?. A la indicada problemática se refiere de forma expresa93, en atención a los documentos contables, la pionera STC 76/1990, rechazando contundentemente que la aportación de tales documentos vulneren el derecho constitucional de declarar contra sí mismo, aunque en este extremo debemos matizar la tesis vertida por nuestro Tribunal Constitucional en la Sentencia de referencia, ya que la misma es la contraria a la mantenida por el Tribunal Europeo de Derechos Humanos ${ }^{94} \mathrm{y}$, sin excesivos esfuerzos interpretativos, a la sostenida por el propio Tribunal Constitucional español en la Sentencia $161 / 199795$.

A modo de cierre de las precisiones que sintetizan el contenido esencial del derecho analizado, debemos de plantearnos una última cuestión que a nuestro juicio resulta de extraordinaria importancia a los efectos del presente trabajo: ¿el contenido esencial de los principios señalados, se focaliza en un derecho a no aportar bajo coacción información autoincriminatoria, o a un derecho a que tal información no se utilice en un procedimiento punitivo? Aunque según hemos mantenido en otro lugar ${ }^{96}$, nuestra opinión ante el indicado interrogante, coincidía con Aguallo y García Berro Aguallo Avilés y García Berro97, al sostener que el alcance de tales derechos, no exige el deber de no aportar, sino la obligación del ente público de no sancionar con base a los datos por ellos

93. Como hemos desarrollado en otro lugar: López Martínez (2003).

94. López Díaz (2000) p. 137 y ss.; Del Pozo López (2000) p. 20; Ribes Ribes (2000) p. 105 y ss.

95. Aunque es posible, como hemos analizado en otro lugar - López Martínez (2003), que se puedan conciliar ambas, ya que los pronunciamientos de los distintos Tribunales ponen énfasis, respectivamente, en el procedimiento de regularización de la deuda tributaria y en el de imposición de la sanción. La posición opuesta a la aquí mantenida parece ser la defendida por Sanz Díaz-Palacios (2002) p.43.

96. López Martínez (2003)

97. Aguallo Avilés y García Berro (2000) p. 75 y ss. 
aportados $^{98}$, desde la perspectiva en la que enfocamos el presente trabajo, hemos de señalar con Palao Taboada, que la forma de tutelar el derecho dependerá de cómo se articulen las relaciones entre el procedimiento de regularización y los procedimientos o procesos punitivos ${ }^{99}$.

Y ello, porque coincidimos plenamente con Lozano Serrano en que debemos superar la dialéctica del pretendido conflicto existente entre el deber de colaboración y el derecho a no autoincriminarse haciendo prevalecer a uno frete al otro, ya que a efectos de la tutela de las garantías y de los derechos que han de ser operativos en el procedimiento y en el proceso, resulta más aconsejable profundizar en sus contenidos y exigencias "para que ambos puedan definirse a la vista y en la consideración del otro"100.

El deber de colaboración opera sobre los procedimientos aplicativos del tributo y sobre las potestades administrativas de la Administración para llevarlos a cabo; el derecho a no autoinculparse, opera en el ámbito del "Ius puniendi" del Estado, es decir, en el procedimiento penal o administrativo sancionador. En consecuencia101 ,la teórica ponderación de los principios sólo habrá de realizarse, si existen bienes y valores constitucionales en colisión.

Y a estos efectos, se ha de dejar claro que cuando se solicitan datos en el procedimiento de regularización con la amenaza de una sanción ante el incumplimiento de dicho deber de colaboración, se está cumpliendo con el deber de contribuir al sostenimiento del gasto público. Si dichos datos, tienen, además de la transcendencia tributaria, una repercusión punitiva, sobre los mismos confluye, si son datos aportados por el propio

98. Ya que como ha afirmado nuestro Tribunal Constitucional, en relación al principio de presunción de inocencia, con el que, según veíamos, también están directamente conectados los principios de referencia, sólo se lesiona el mismo cuando existe condena sin pruebas o con aquéllas que han sido irregularmente obtenidas. STC 71/ 1994, de 3 de marzo. F. J. VIIo

99. Palao Taboada (2013) p. 36.

100. Lozano Serrano (2015) p. 27. Y junto a esta premisa metodológica, señala que es igualmente esencial, para abordar el eventual conflicto, seguir la guía que significa la jurisprudencia del Tribunal Europeo de derecho Humanos, no solo porque ella fue la que suscitó el problema, sino porque nuestra Constitución obliga explícitamente -art. 10.2- a seguir sus interpretaciones en materita de derechos fundamentales, a tenor del CEDH, suscrito por España y también hoy, de la Carta de derechos Fundamentales de la Unión Europea (p. 28 y ss.). 101. Como hemos analizado en otro lugar. López Martínez (2003) p. 257 y ss. 
sujeto102, el derecho a no autoinculparse, pero no necesariamente entra en conflicto con el deber de contribuir; sób b hará, si son incorporados al procedimiento sancionador 0 al proceso penal y sirven como fundamento para la correspondiente sanción. Es decir, exactamente como se viene aplicando en nuestro actual Derecho positivo ${ }^{103}$.

Siendo ello cierto, no lo es menos, que si realizamos un análisis de los principios aplicables en cada instrucción y de las respectivas normativas que la regulan, no encontramos razones jurídicas que avalen necesariamente tal proceder: en el procedimiento de regularización, en el Inspector o en cualquier otro, se obtienen datos que no son necesariamente fruto del deber de colaborar del presunto futuro imputado sino de terceras personas o de las actuaciones directas de obtención de información, de comprobación e investigación por parte del órgano administrativo, y dichos datos, así como aquéllos obtenidos en cumplimiento de los deberes de colaboración del propio sujeto afectado, siempre que éste, una vez informado al respecto, preste su aquiescencia a su posterior utilización, pueden incorporarse formalmente al expediente punitivo sin producir la limitación de ningún derecho104.

Dicho en otros términos, es imprescindible que el propio legislador -y no solo el operador jurídico- sea quien diseñe la hipotética ponderación de intereses aludida, y lo ha de hacer a la hora de regular con pulcritud las relaciones que se han de establecer entre la instrucción de los procedimientos aplicativos de los tributos y de los procedimientos o procesos sancionadores o penales, y la articulación de estas relaciones, o la aplicación de su inexistencia, ha de ser controlada por nuestro Tribunal Constitucional, y para ello nuestro Máximo Intérprete ha de precisar si los derechos y valores en conflicto, son susceptibles de ser limitados, y ha de hacerlo, en función de sus respectivos contenidos constitucional y esencial.

Siguiendo esta metodología de trabajo ${ }^{105}$, la solución al pretendido problema queda expedita si tenemos en cuenta que el derecho a no autoinculparse

102. Del Pozo López (2000) p. 33.

103. Por esta razón, es claro que si bien el derecho a no autoincriminarse, no es aplicable, a nivel de principio en los procedimientos de aplicación tributaria, en a tención a la propia jurisprudencia del TEDH, sí lo será, cuando la ley nacional prevé que los datos obtenidos en ellos puedan trasladarse o usarse en los procedimiento o procesos punitivos "aun sin haberse dado en el caso concreto la utilización efectiva de los mismos" (Lozano Serrano (2015) p. 29).

104. Aguallo Avilés y García Berro (2000) p. 122 y ss.

105. En esta misma línea López Martínez (2016). 
forma parte de aquel elenco de principios no susceptibles de limitación, con lo que hemos de concluir, que si bien es cierto que no debería ser alegado en el procedimiento de regularización tributaria, donde los intereses confluyen, pero no colisionan, obviamente hasta que se presenta la «noticia criminis» y muta la naturaleza del procedimiento, no puede ser ponderado en el proceso penal y, en consecuencia, de no anticiparse, con el consiguiente derecho a la información en este preciso momento, la única solución constitucional posible es la no utilización de los datos obtenidos con amenaza de sanción en el proceso ${ }^{106}$.

Teniendo en cuenta cuanto antecede, hemos de sostener que la comunicación de datos y pruebas entre una y otra instrucción, no limita de partida, ni la necesaria realización de ambas instrucciones, ni su carácter independiente. Precisamente, porque lo que debemos de demandar, con carácter prioritario -y en cumplimiento de las normas que los regulan- es que se realice, en el procedimiento de regularización, pero también en el proceso, una verdadera fase de instrucción en la que resulten operativos los derechos y las garantías, pero también las facultades y los poderes propios de cada orden.

En consecuencia, hemos de sostener que la defectuosa articulación jurídica de las relaciones entre procedimiento y proceso, es la que está provocando que en la aplicación práctica de las normas antes y después de la reforma -que una vez más obvia ésta problemática- la colisión de principios sea tan real como lo es la propia lesión de los Derechos Fundamentales en las relaciones estudiadas. Y son estos defectos legislativos y normativos existentes los que debemos de denunciar. Denunciemos en consecuencia, el torpe voluntarismo del legislador y su visión estrictamente recaudatoria, también de los procedimientos punitivos. No obstante, con igual ímpetu hemos de demandar coherencia con los principios aplicables y con las propias Leyes sectoriales vigentes, en la aplicación de las normas que pretendidamente se han promulgado para conseguir la separación y la independencia de los procedimientos y procesos como fórmula de evitar la contaminación de los principios operativos de uno y otro, porque, según pensamos, la aplicación que se hace de la normativa en vigor, ni es la más acorde con la regulación de las relaciones entre procedimiento y proceso, ni la más respetuosa con los intereses y principios que se han de defender desde los estrictos parámetros constitucionales.

106. Con ello, como decíamos en otra parte del presente trabajo, se consagra el principio de adecuación al fin y se respetan escrupulosamente los intereses que pudieran entrar en conflicto: alcanza su plena operatividad el deber de contribuir, con el establecimiento de los deberes de colaboración, que no colisionan con el derecho a no autoinculparse en el Ordenamiento punitivo sancionador. 
En efecto, como hemos señalado en otro lugar107 la defectuosa construcción normativa, la parquedad legal, incluso, en ocasiones, su ambigüedad calculada, han de hacer acreedor al legislativo, al titular de la potestad reglamentaria y también a los diferentes operadores jurídicos que aplican la meritada normativa, del correspondiente reproche científico108. Pero ello, siendo cierto, no nos puede conducir a desconocer el mal uso de las normas, que de facto se está produciendo en la actualidad, mal uso, que ha de ser combatido con las armas que el Estado de Derecho nos concede y que pueden ser bastante más eficaces que el reproche genético a la normativa vigente.

La solución a los estudiados problemas, solo puede venir de la mano de determinar el alcance y el contenido de los principios aplicables en las diferentes instrucciones, y en este orden de consideraciones, hemos de volver a poner de manifiesto, ahora desde la perspectiva a la que nos conduce esta metodología de trabajo, que el doble contenido del derecho a no autoincriminarse ${ }^{109}$ habrá de ser operativo, en función de la articulación de las relaciones objeto de nuestro estudio. Si existen instrucciones separadas, la primera dimensión -derecho a guardar silencio- solo sería exigible en el proceso penal, siempre que se garantizase la segunda -no utilizar la información autoincriminatoria en el proceso punitivo; no obstante en situaciones como la contemplada por nuestro derecho positivo en las que existe una teórica separación, condicionada por la total comunicación de datos entre uno y otro, la única forma de garantizar los derechos del imputado es reconocerle su derecho a guardar silencio en el procedimiento de regularización.

El problema esencial que debería resolver la normativa que regula las relaciones estudiadas, como única forma de proteger los intereses, derechos y garantías del obligado, de la Administración y de la Jurisdicción, es el de precisar el momento y el alcance del ejercicio del derecho a no autoincriminarse en el sentido indicado líneas arriba.

En relación al momento, como anticipábamos, ha de ser como mínimo, desde el preciso instante en el que aparece la «noticia criminis». Palao Taboada, sostiene la tesis que desde el inicio del procedimiento de regularización, básicamente, porque la propia esencia del derecho a guardar silencio, no depende

107. López Martínez (2016).

108. En esta misma línea nos remitimos in extenso a nuestro trabajo, López Martínez, (2001) p. 504 y ss 109. El derecho a no declarar contra sí mismo -a guardar silencio- y el derecho a que la información autoincriminatoria obtenida bajo coacción se utilice como prueba de cargo en un proceso penal. 
del contenido de la información que se rehúsa - por trivial e irrelevante que parezca- por cuanto que sólo el obligado conoce si la información que se le requiere tiene alcance autoincriminatoria ${ }^{110}$. Se trata, como el propio autor indica, de aplicar las coordenadas establecidas en el modelo Alemán en el que existe comunicación plena entre ambas instrucciones, pero para preservar los principios y derechos en juego, se prohíbe, en regularización, el uso de medidas coercitivas frente al obligado y, a la inversa, no será posible utilizar, para la determinación de la deuda tributaria, los medios de investigación reservados en las instrucciones de corte punitivo. Son los principios de «adecuación al fin» y de «claridad procedimental», en consecuencia, los que ordenan la articulación de las relaciones entre procedimiento y proceso, con el máximo respecto a los principios aplicables ${ }^{111}$.

En relación al alcance material del derecho, conviene precisar a qué tipos de datos alcanza el derecho a no autoinculparse y, para ello, nada mejor que hacer nuestras las consideraciones realizadas por el profesor Lozano Serrano al señalar que su ámbito de aplicación, no crearía conflictos con la exigencia bajo sanción de la solicitud de justificantes o aclaraciones de lo presentado previamente por el obligado en sus declaraciones, tampoco aquellas solicitudes de datos cuyo registro o contabilización viene obligado por ley, o para constatar circunstancia que la Administración ya conoce por su propia labor en el ejercicio de sus funciones y facultades o por deberes de colaboración del propio obligado o de terceras personas, "en todo caso, siempre que tales datos y justificantes se refieran a los que debería integrar la declaración o autoliquidación, es decir, datos «determinantes de la obligación tributaria» que se está comprobando o sobre cuyo posible incumplimiento se esté instruyendo el procedimiento sancionador o el proceso penal"112.

110. Palao Taboada (2013) p. 37.

111. A todo lo anterior, debemos indicar, (con Palao Taboada (2013) p. 40 y ss.) que en el derecho español, si bien las facultades del juez instructor, difieren claramente de las que tiene la Administración tributaria en la regularización de la deuda, no ocurre lo mismos entre regularización y procedimiento sancionador tributario. Por ello, en nuestro modelo de relaciones, los indicados principios han de ser especialmente aplicables, y en especial, a toda la actividad realizada en sede de regularización desde que aparece el primer indicio de la existencia de la «noticia criminis».

112. Lozano Serrano (2015) p. 35. 
Sentadas las implicaciones de la incorporación de datos y pruebas desde los procedimientos de regularización de deudas en relación con el derecho a no autoinculparse y la importancia que en su análisis tiene el instante de la existencia de la «noticia criminis», estamos en condiciones de retomar algunas cuestiones que quedaron pendientes y que presentamos a manera de corolario necesario a la problemática que venimos analizando:

La primera de ellas, el alcance de la propia incorporación formal de los datos y pruebas obtenidos en el procedimiento de regularización, ha quedado determinada en la interpretación que realizábamos líneas arriba para hacer compatibles los principios estudiados. En consecuencia, como «noticia criminis», se incorporarán todos aquellos datos y pruebas que determinen la acusación, salvo aquéllos que hayan sido obtenidos en el procedimiento de regularización como consecuencia del cumplimiento de los deberes de colaboración exigidos bajo la amenaza de sanción y sin el pertinente ejercicio del derecho a la información. Incluso, aquéllos que hayan sido aportados voluntariamente por el obligado tributario en el curso de las actuaciones de regularización ${ }^{113}$.

En segundo lugar, se habrá de advertir al inicio de las actuaciones de regularización, y siempre cuando mutan su naturaleza por la aparición de la «noticia criminis», de que todas las informaciones aportadas voluntariamente en el curso de las actuaciones de regularización podrán ser incorporadas en el hipotético proceso punitivo que se derive de su resultado.

Por último, como también anticipamos ${ }^{114}$, como la reforma incorporada en el modelo de relaciones entre sedas instrucciones no aborda los problemas estudiados que se ponen en evidencia en las relaciones entre procedimiento y proceso, debemos dejar claro, con Lozano Serrano, que el derecho a la no autoinctiminación, obviamente ha de estar presente en el procedimiento de liquidación derivada de las nuevas relaciones -singularmente en la liquidación de la cuota vinculada al delito- pues "bastaría la coexistencia de procedimientos para apreciar el riesgo autoincriminatorio en la obtención de datos y pruebas del propio sujeto bajo coerción en el seno del procedimiento tributario"115.

112. Lozano Serrano (2015) p. 35.

113. Falcón y Tella (1998) p. 492. En esta misma línea, López Martínez (2016).

114. López Martínez (2016).

115. Lozano Serrano (2015) p. 32. 
iii. A modo de conclusión

Por la índole del presente estudio, nos hemos limitado a presentar los elementos nucleares de tres de los problemas que conforman el eje principal que debe vertebrar las relaciones entre el procedimiento de regularización de deudas y el proceso por delito frente a la Hacienda Pública en el reino de España116. Hemos pretendido presentar, desde los condicionamientos fácticos que origina la existencia de un umbral económico para que la falta de ingreso adquiera relevancia penal, no solo las conexiones objetivas que se dan en la instrucción del procedimiento de regularización y proceso, sino sobre todo, la diferente posición jurídica del obligado tributario y del imputado, y lo hemos hecho desde la convicción de que procedimiento y proceso responden a finalidades claramente diferentes, se rigen por normas y técnicas distintas y, en su seno, se han de proyectar principios que en ocasiones resultan de difícil conciliación.

El eje central de nuestras consideraciones se encuentra en el hecho de que las normas que dicen regular las relaciones entre procedimiento y proceso, establecen la comunicabilidad absoluta de datos y pruebas en las instrucciones desarrolladas - 0 al menos resultan tan genéricas que las permiten-. Lo anterior supone el uso de datos y pruebas obtenidos en la regularización, con sus propias potestades y principios, en el proceso penal en el que resultan operativos otros poderes y otros principios. Este dato, que constituye el núcleo de la ordenación de las relaciones objeto de estudio, obliga, por un lado, para garantizar los derechos del futuro imputado, a que los principios del "ius puniendi" sean operativos en el procedimiento de regularización; y por otro, a que los datos y las pruebas obtenidos en regularización, sean valorados por el juez instructor, desde la prejudicialidad tributaría, pero con el valor de la prueba y de la carga de la prueba que ha de resultar operativa en la instrucción de un proceso penal.

Este modelo de relaciones que proponemos, no pretenden, como pudiera pensarse, que el legislador y el operador jurídico tengan que elegir entre regularización o proceso, sino que aspira a que se adopten las medidas legislativas

116. Existen otras muchas cuestiones que han quedado en el tintero: como las dificultades de diferenciar el alcance de la deuda vinculada al delito y de la deuda no vinculada y sus complejas interconexiones; la propia naturaleza de la liquidación de la deuda vinculada al delito; el significado y alcance del recuperado trámite de audiencia; las repercusiones constitucionales de la recaudación ejecutiva de una liquidación no definitiva y la propia condición de garante del juez instructor del proceso; la importancia de las medidas cautelares para garantizar la tutela judicial efectiva; las limitaciones de recurso de la liquidación de la deuda vinculada al delito. 
necesarias para que en ambos órdenes se cumplan los principios que rigen las distintas instrucciones en nuestro ordenamiento117. En definitiva, se trata de regularizar el cumplimiento de las obligaciones fiscales, con el ejercicio de las potestades y los deberes que el ordenamiento prevé en el seno de los procedimientos de aplicación tributaria, con escrupuloso respeto a sus fines y principios y con el imperativo deber de eficacia que los intereses que protegen impone. Y supone también, sancionar los comportamientos de los defraudadores en el seno de los procedimientos y procesos punitivos previstos por el Ordenamiento a tal fin, con sus principios y en el escrupuloso cumplimiento de los derechos fundamentales consagrados por nuestra Constitución. Es posible, como hemos tenido la oportunidad de señalar en otro lugar118 que para ello, se deba alterar la estrategia de investigación tanto en el curso del procedimiento de regularización como en el proceso o en el sancionador tributario119, localizando pruebas y fundamentos en actuaciones directas de información, comprobación o investigación, en deberes de colaboración de terceras personas120, pero ello, no ha de interferir en la eficacia de la potestad sancionadora de las Administraciones Públicas, menos aún en la instrucción de un proceso penal, cuya primera piedra, ha de ser, precisamente, el escrupuloso respecto a los derechos y principios del "Ius puniendi" del Estado.

Para conseguir dicho objetivo, el legislador ha de afrontar decididamente todas estas cuestiones, y son sobre ellas sobre las que debería centrarse a la hora de regular el tránsito de los procedimientos de aplicación de los tributos a los procesos penales. No obstante, como hemos intentado poner de manifiesto a lo largo del presente trabajo, los aspectos más importantes de estas relaciones son ignoradas por tanto por la anterior normativa como por la nueva legislación, a pesar que en ella se incluya todo un Título VIạ, de nuevo cuño, que lleva por rúbrica «actuaciones y procedimientos de aplicación de los tributos en los supuestos de delitos contra la Hacienda Pública». Una vez más la visión cortoplacista de la recaudación ha impedido la articulación jurídica de las relaciones que viene demandando nuestro sistema.

117. Herrera Molina (1997) p. 154.

118. López Martínez (2016).

119. Del Paso Bengoa (2001) p. 96 . Y Márquez Márquez (1999) p.41 y ss.

120. Sanz Díaz-Palacios (2002) p. 52. 
Como hemos señalado en otro lugar ${ }^{121}$, cualquiera que sea el modelo de relaciones que se adopte, el conjunto de problemas que hemos presentado han de quedar resueltos, y se ha de hacer sin ambigüedades, sin renunciar a la eficacia en la recaudación de los recursos públicos -singularmente los tributarios- en el cumplimiento del deber de contribuir, con todas su prerrogativas intactas, pero sin que esta pretendida eficacia traspase a los procesos de corte punitivo, que han de regirse con sus principios garantistas, pues aquí hablamos de represión e intimación, objetivos que se casan mal con la pretendida eficacia administrativa, que una vez más sirve de coartada, para no regular adecuadamente las relaciones entre ambas instrucciones, legislando a golpe de eficacia recaudadora en regularización, pero también en los procesos penales ${ }^{122}$. Antes al contrario, si no se produce la articulación jurídica entre el procedimiento y proceso que venimos demandando solo conseguiremos proporcionar su respectiva coartada a los defraudadores, que con la pretensión de ver garantizados sus derechos de corte punitivo, los oponen, sistemáticamente, y con sus propios intereses, en los procedimientos aplicativos de los tributos.

El conjunto de problemas que hemos abordado en el presente trabajo no son nuevos en nuestro ordenamiento, no han irrumpido de manera brusca, de forma que la respuesta no haya podido ser pensada, reflexionada, y aunque pudiera ser cierto que la aplicación de los principios de corte garantista vigentes en las diferentes manifestaciones del "Ius puniendi" del Estado, en los procedimientos de regularización tributaria que vienen exigidos por el modelo de relaciones establecido en nuestro ordenamiento, afecten a la eficacia recaudatoria, somos muchos los que seguimos pensando, y escribiendo ${ }^{123}$ que la mejor forma de atentar contra la recaudación es colocarla como eje sobre el que ha de girar toda la producción normativa. Mucho nos tememos que una vez más, la reforma recién incorporada en el ordenamiento español en relación a esta materia, ha vuelto a cometer los mismos errores que, de nuevo, queremos denunciar desde estas líneas.

121. López Martínez (2016).

122. Pérez de la Vega (2014) p. 166 y ss.

123. López Martínez (2016). 


\section{REFERENCIAS BIBLIOGRAFICAS}

AgUALLo AvilÉS, Ángel y GARCÍA BERRO, Florián (2000): El deber de colaborar con la Administración tributaria y el derecho a no autoinculparse: un conflicto aparente. El asesor fiscal ante el nuevo siglo (Madrid, AEDAF).

ANEIROS PERIEIRA, Jaime (2002): "El derecho a no declarar contra sí mismo y a no confesarse culpable a la luz de la Jurisprudencia del Tribunal Europeo de Derechos Humanos". En Revista Quincena Fiscal, Editorial Arandazi, año XI, № 17, pp. 9-23. Ayats Vergés, Miro y De JuAn CASAdevalL, Jordi (2013): Informe sobre las novedades introducidas en la nueva regulación del delito Fiscal: algunas propuestas de mejora (Madrid, Editorial Fundación Impuestos y Competitividad).

BELTRÁN GIRÓN, Fernando (2012): "El proyecto de reforma del art. 305 del CP: principales novedades". En Carta Tributaria. Monografías, año XXIII, № 20, pp. 11-30.

CAAMAÑO ANIDO, Miguel (2002): "El derecho tributario sancionador desde la perspectiva del ordenamiento comunitario (I y II)". En № 237 y 238, pp. 93-126. CALVO VÉRGEL, Juan (2014): “Las competencias de investigación patrimonial atribuidas a la Administración tributaria en los procesos por delitos contra la hacienda Pública”. En Rev. Jurídica de la región de Murcia, año XXIX, № 47, pp. 1-21.

Del PASO BenGOA, Jesús María (2001): "Relaciones entre el procedimiento inspector y el procedimiento sancionador administrativo". En Instituto de Estudios Fiscales. Principios, derechos y garantías constitucionales del régimen sancionador tributario. Documentos de trabajo del IEF. Segundas Jornadas sobre el Derecho Constitucional Tributario, Doc. 19/ 2001 (Madrid, Instituto de Estudio fiscales, Vol. I), pp. 67- 96.

Del Pozo LóPEZ, M. (2000): “El derecho a no autoinculparse y a no declarar contra si mismo. Reflexiones sobre su aplicación en el Derecho Tributario". En Revista. Jurisprudencia Tributaria, Editorial Arandazi, № 7.

FALCóN y TELLA, Ramón (1998): "La incompatibilidad de utilizar los datos obtenidos por la Inspección tributaria a efectos penales o sancionadores: La Sentencia Saunders, de 17 de diciembre de 1996". En Associação Fiscal Portuguesa e Instituto Latinoamericano de Derecho Tributario. La criminalización de las infracciones fiscales (Lisboa, Associação Fiscal Portuguesa e Instituto Latinoamericano de Derecho Tributario, Tomo II).

FUSTER ASENCIO, Consuelo (2001): El procedimiento sancionador tributario (Navarra, Editorial Aranzadi).

GONZÁLEZ MONTES, José Luis: (1990) "La prueba obtenida ilícitamente con violación de los derechos fundamentales" (El derecho constitucional a la prueba y sus límites)" En Revista de Derecho Procesal, Revista Iberoamericana de Derecho Procesal, N¹, 1990, pp. 29-44. 
HERRERA MoLINA, Pedro Manuel (1997): “Los derechos a guardar silencio y a no declarar contra sí mismo en el procedimiento inspector -Comentario y traducción de la STEDH de 17.XII.1996 Saunders v. United Kingdom". En Impuestos: Revista de doctrina, legislación y jurisprudencia, Wolters Kluvers, año XIII. №2, pp. 16-17. IGESIASCAPELLAS, Joan (2013-a): “Efectos del proceso penal por delitos contra la Hacienda Pública sobre el procedimiento de inspección tributaria". En Estudios Financieros. Revista de Contabilidad y Tributación: Comentarios, Casos Prácticos, Centro de Estudios Financieros, № 359, pp. 103-149.

IGESIAS CAPELLAS, Joan (2013-b): "La denuncia Administrativa de la defraudación tributaria constitutiva de delito contra la Hacienda Pública”. En Estudios Financieros. Revista de Contabilidad y Tributación: Comentarios, Casos Prácticos, Centro de Estudios Financieros, № 367, pp. 97-140.

IGESIAS CAPELLAS, Joan (2013-c): “La prejudicialidad tributaria en el proceso penal por delito contra la Hacienda Pública". En Impuestos: Revista de doctrina, legislación y jurisprudencia, Wolters Kluvers, año XXIX, № 3, pp. 13-46. LÓPEZ DíAz, Antonio (2000): El derecho a no autoinculparse y a no declarar contra sí mismo en el procedimiento sancionador en materia tributaria" En López Díaz, Antonio y García Novoa, César (coords.). Temas de derecho penal tributario (Madrid, Editorial Marcial Pons), pp. 53-78.

LÓPEZ DíAZ, Antonio (2015): “Procedimientos Tributarios y delito fiscal en el proyecto de reforma de la LGT". En Civitas. Revista Española de Derecho Financiero, Editorial Civitas, año XVI, № 167, pp. 15-44.

LÓPEZ MARTíNEZ, Juan (2001-a): "El derecho a no autoinculparse y el intercambio de datos entre el procedimiento inspector y el sancionador tributario" en Zugaldía Espinar, José Miguel y Roca Roca, Eduardo (Coords): Los Derechos Humanos. Libro homenaje al Sr. D. Luis Portero García (Granada, Universidad de Granada).

LÓPEZ MARTíNEZ, Juan (2001-b): "El intercambio de datos entre el procedimiento de regularización y el sancionador tributario". En Revista Tributos Locales, Renta grupos locales, año II, № 12.

LÓPEZ MARTínEZ, Juan (2003): El Ius Puniendi del Estado en el Ordenamiento sancionador tributario (Análisis de los principios del primero en la articulación jurídico-positiva del segundo Obra inédita) (Granada, Ejercicio de Cátedra).

LÓPEZ MARTíNEZ, Juan (2008): “La necesidad de un auténtico procedimiento sancionador separado como garantía de la existencia del procedimiento sancionador Tributario". En Revista Técnica Tributaria, Asociación Española de Asesores Fiscales, Año XXI, № 82, pp. 103-134.

López MARTíneZ, Juan (2016): "Problemas pendientes en las relaciones entre la regularización tributaria y el proceso penal a la Luz de la reforma de la Ley Ceneral Tributaria”. En Revista Quincena Fiscal, Editorial Aranzadi, año XXIV, Nº 4. 
LÓPEZ MoLINO, Antonio María (1998): Régimen jurídico de la prueba en la aplicación de los tributos (Pamplona, Editorial Aranzadi).

LozAno Serrano, Carmelo (2015): "El deber de colaboración tributaria sin autoincriminación". En Revista Quincena Fiscal, Editorial Aranzadi, año XXIV, № 8, pp 19-39.

MARTíN QuERALT, Juan (1998) “Los registros de almacenes, locales comerciales y fábricas en el proceso tributario-penal”. En Tribuna Fiscal. Revista Tributaria y Financiera, Ciis Praxis, año IX, № 89.

MARTín QuERALT, Juan (2015) "El derecho de defensa en materia tributaria”. En Tribuna Fiscal. Revista Tributaria y Financiera, Ciis Praxis, año № 277, pp. 4-8. MÁRQUEZ MÁrqUEZ, Antonio (1999): "La Inspección de los Tributos y el nuevo procedimiento sancionador tributario". En Estudios Financieros. Revista de contabilidad y tributación. Comentarios, casos prácticos. Centro de Estudios Financieros № 193, pp. 35-54.

MIRANDA ESTRAMPES, Manuel (1999): El concepto de prueba ilícita y su tratamiento en el proceso penal (Barcelona, Editorial Bochs).

MONTERO DOMínGUEZ, Antonio (2012) "la proyectada reforma de la regulación del delito contra la hacienda Pública". En Tribuna Fiscal. Revista Tributaria y Financiera, Ciis Praxis, año № 263.

MonTERo DomíngueZ, Antonio (2015) La ley General Tributaria. La Reforma tributaria (Valencia, Editorial Tirant Tributario).

MORENO CATENA, Victor (2014): "La dudosa constitucionalidad de las medidas cautelares ordenadas por la Agencia tributaria durante el proceso penal”. En Revista Diario de la Ley, Wolters Kluwer, año IX, № 8331.

NAVARRO EGEA, Mercedes (2001): "Notas sobre la conformidad del interesado con las actas de inspección (II)”. En Revista Quincena Fiscal, Editorial Arandazi, año X, № 10, pp. 9-24.

PALAO TABOADA, Carlos (2013) "El derecho a no autoinculparse en el ámbito tributario: una revisión". En Civitas. Revista Española de Derecho Financiero, Editorial Civitas, año XXXV, № 159, pp. 23-59.

PALAO TABOADA, Carlos (2015): "Los procedimientos de aplicación de los tributos en supuestos de delitos contra la Hacienda Pública en el Proyecto de Ley de Modificación de la LGT". En Civitas. Revista Española de Derecho Financiero, Editorial Civitas, año XXXVII. № 167, pp. 45-74.

PÉREZ NiETo, Rafael (2013): Informe sobre derecho sancionador tributario (Valencia, Editorial Foro Jurídico).

PÉREZ DE LA VEGA, Leonor María (2014): "Alcance de la ley 7/ 2012, de lucha contra el fraude fiscal, en la práctica del embargo por deudas tributarias". En Revista Crónica Tributaria, № 150, pp.165- 196. 
Polo SoRIANO, Alfonso. (1986): "La presunción de veracidad de los documentos de la Inspección". En Impuestos: Revista de doctrina, legislación y jurisprudencia, Wolters Kluvers, año III, № 10.

PONT I CLEMENTE, Joan Francesc (1987): “La supresión de la prejudicialidad necesaria en el proceso penal tributario". En Revista de derecho Financiero y Hacienda Pública, № 192.

RANACAÑO MARTíN, María Asunción (2014): “El progresivo distanciamiento dogmático entre el ilícito penal y el ilícito tributario". En Revista Quincena Fiscal, Editorial Arandazi, año XXII, № 15-16., pp- 89-116.

RODRÍGUEZ SOL, Luís (1988): Registro domiciliario y prueba ilícita (Granada, Editorial Comares).

RIBES RIBES, Aurora (2000): “El derecho a no declarar contra sí mismo en el ámbito penal tributario: Reflexiones a la luz de la jurisprudencia norteamericana”. En Civitas. Revista Española de Derecho Financiero, Editorial Civitas, año XXVI, № 105, pp. 105-119.

RUBiO MONTIEL, Bonifcio (2012): “El deber de colaboración con la inspección tributaria frente al derecho a no declarar contra sí mismo". Revista de Contabilidad y Tributación. № 356, pp. 33-72.

RUIZ GARCíA, José Ramón (2011): “La relación entre el procedimiento de Inspección y el proceso penal por delito contra la Hacienda Pública”. En Civitas. Revista Española de Derecho Financiero, Editorial Civitas, año XXXVII, № 151, pp. 775-724.

RUIZ GaRCíA, José Ramón (2013) "Hacia un nuevo marco de relaciones entre el procedimiento de inspección tributaria y el proceso penal por delito contra la Hacienda Pública". En Estudios Financieros. Revista de Contabilidad y Tributación: Comentarios, Casos Prácticos, Centro de Estudios Financieros, № 365-366, pp. 57-82.

SÁNCHEZ PEDROCHE, José Andrés (2001): “La culpabilidad en el procedimiento sancionador tributario". En Revista Tributos Locales, Renta grupos locales, año II, №8.

SANZ DíAZ-PALACIOS, José Alberto (2002): "En busca del necesario equilibrio entre el deber de colaborar con la Inspección tributaria y el derecho a no autoinculparse". En Impuestos: Revista de doctrina, legislación y jurisprudencia, Wolters Kluvers, año XVIII, № 14, pp. 443-462.

SANZ Díaz-PALACIOS, José Alberto (2012): "El derecho de los contribuyentes a no autoinculparse en el asunto Chambaz contra Suiza (Comentario de la STEDH de 5 de abril de 2012)" En Tribuna Fiscal. Revista Tributaria y Financiera, Ciis Praxis, año XXV, №. 263, pp. 25-30.

Siles CANTERO, Antonio (1995): “Las actas de la Inspección como medio de prueba”. En Impuestos: Revista de doctrina, legislación y jurisprudencia, Wolters Kluvers, año XII, № 1, pp. 85-114. 
TEJERIZO LÓPEZ, José Manuel (1984): "El principio de tutela judicial efectiva y los procedimientos tributarios". En Civitas. Revista Española de Derecho Financiero, Editorial Civitas, año XX, № 82, pp.265-294.

TORRES RoselL, Nuria (1991): La denuncia en el proceso penal (Madrid, Editorial Montecorvo, S.A.).

ZORNOZA PÉREZ, Juan (1992): El sistema de infracciones y sanciones tributarias (los principios constitucionales del derecho sancionador (Madrid, Ed. Civitas). 